\title{
Quellen- und Literaturverzeichnis
}

A., R., »Gebt uns eine Chance!«, in: Der Ruf 23 (1947), H. 2, S. 7.

Ackermann, Ulrike, Sündenfall der Intellektuellen. Ein deutsch-französischer Streit von 1945 bis heute. Mit einem Vorwort von François Bondy, Stuttgart 2000.

Agee, Philip, Central Intelligence Agency, Massenmedien als Transportmittel für USInteressen, in: Ekkehardt Jürgens/Eckart Spoo (Hg.), Unheimlich zu Diensten. Medienmißbrauch durch Geheimdienste, Göttingen 1986, S. 21-35.

Allemann, Fritz René, Bonn ist nicht Weimar, Köln/Berlin 1956.

Andrew, Christopher, Oleg Gordiewsky, KGB. Die Geschichte seiner Auslandsoperationen von Lenin bis Gorbatschow, München 1990.

Arendt, Hannah, Der Liebesbegriff bei Augustin. Versuch einer philosophischen Interpretation, Berlin 1929.

Dies., Organisierte Schuld, in: Die Wandlung 1 (1946), H. 4, S. 333-330.

Dies., Über den Imperialismus, in: Die Wandlung 1 (1946), H. 8, S. 650-666.

Dies., Konzentrationsläger, in: Die Wandlung 3 (1948), H. 4, S. 309-330.

Dies., Parteien und Bewegungen, in: Die Wandlung 4 (1949), H. 4, S. 459-473.

Dies., Es gibt nur ein einziges Menschenrecht, in: Die Wandlung 4 (1949), Herbsth., S. $754-770$.

Dies., Rahel Varnhagen. The Life of a Jewess, London 1958 (dt. Ausg.: Rahel Varnhagen, Lebensgeschichte einer deutschen Jüdin aus der Romantik, München 1959).

Dies., The Human Condition, Chicago 1958 (dt. Ausg.: Vita activa oder Vom tätigen Leben, Stuttgart 1960).

Dies., Die ungarische Revolution und der totalitäre Imperialismus, München 1958.

Dies., Between Past and Future. Six Exercices in Political Thought, New York 1961 (erweit. Aufl. 1968; dt. Ausg.: Zwischen Vergangenheit und Zukunft: Übungen im politischen Denken I. Hg. von Ursula Ludz, München/Zürich 1994).

Dies., On Revolution, New York 1963 (dt. Ausg.: Über die Revolution, München 1963).

Dies., Eichmann in Jerusalem: A Report on the Banality of Evil, New York 1963 (dt. Ausg.: Eichmann in Jerusalem. Ein Bericht von der Banalität des Bösen, München 1964).

Dies., Was bleibt? Es bleibt die Muttersprache. Ein Gespräch mit Günter Gaus, in: Adelbert Reif(Hg.), Gespräche mit Hannah Arendt, München 1976, S. 9-34. 
Dies., Legitimität der Lüge in der Politik? Hannah Arendt in der Diskussion mit Sebastian Haffner, Bernard Vogel und Hans-Friedrich Hölters, in: Adelbert Reif(Hg.), Gespräche mit Hannah Arendt, München 1976, S. 101-126.

Dies., The Life of the Mind, 2 Bde., New York 1978 (dt. Ausg.: Vom Leben des Geistes, Bd. 1: Das Denken, Bd. 2: Das Wollen, München 1979).

Dies., Walter Benjamin, in: Dies., Menschen in finsteren Zeiten. Hg. von Ursula Ludz, 2. Aufl., München 1989, S. 185-242 (amerik. Originalausg.: Men in Dark Times, New York 1969).

Dies., Die Vollendete Sinnlosigkeit, in: Dies., Nach Auschwitz. Essays \& Kommentare 1. Hg. von Eike Geisel und Klaus Bittermann. Aus dem Amerik. übersetzt von Eike Geisel, Berlin 1989, S. 7-30.

Dies., Die Krise des Zionismus. Essays \& Kommentare 2. Hg. von Eike Geisel und Klaus Bittermann. Aus dem Amerik. übersetzt von Eike Geisel. Mit einem Nachwort von Henryk M. Broder, Berlin 1989.

Dies., Frieden oder Waffenstillstand im Nahen Osten?, in: Dies., Israel, Palästina und der Antisemitismus. Hg. von Eike Geisel und Klaus Bittermann. Aus dem Amerik. von Eike Geisel, Berlin 1991, S. 39-75.

Dies., Elemente und Ursprünge totaler Herrschaft, 3. Aufl., München 1993 (amerik. Originalausg.: The Origins of Totalitarianism, New York 1951; dt. Erstausg.: Frankfurt a. M. 1955).

Dies., Was ist Politik? Fragmente aus dem Nachlaß. Hg. von Ursula Ludz. Vorwort von Kurt Sontheimer, München 1993.

Dies., Besuch in Deutschland. Aus dem Amerikanischen von Eike Geisel. Mit einem Vorwort von Henryk M. Broder und einem Porträt von Ingeborg Nordmann, Berlin 1993.

Dies., Gestern waren sie noch Kommunisten (1953), in: Der Freitag, Nr. 27, 28. Juni 1996.

Dies., Vor Antisemitismus ist man nur noch auf dem Monde sicher. Beiträge für die deutsch-jüdische Emigrantenzeitung "Aufbau« 1941-1945. Hg. von Marie Luise Knott, München 2000.

Dies., In der Gegenwart. Übungen im politischen Denken II. Hg. von Ursula Ludz, München 2000.

Dies., Denktagebuch. 1950-1973. Hg. von Ursula Ludz und Ingeborg Nordmann, in Zusammenarbeit mit dem Hannah-Arendt-Institut, Dresden, 2 Bde., München 2002.

Dies./Jaspers, Karl, Briefwechsel 1926-1969. Hg. von Lotte Köhler und Hans Saner, 3. Aufl., München 1993.

Aron, Raymond, Deutschland, Juni 1932, in: Joachim Stark (Hg.), Raymond Aron: Über Deutschland und den Nationalsozialismus. Frühe politische Schriften 1930-1939, Opladen 1993, S. 100-110.

Ders., Die nationale Revolution in Deutschland (September 1933), in: Joachim Stark (Hg.), Raymond Aron: Über Deutschland und den Nationalsozialismus. Frühe politische Schriften 1930-1939, Opladen 1993, S. 141-154.

Ders., Eine anti-proletarische Revolution. Ideologie und Wirklichkeit des Nationalsozialismus (1935), in: Joachim Stark (Hg.), Raymond Aron: Über Deutschland und den Nationalsozialismus. Frühe politische Schriften 1930-1939, Opladen 1993, S. $167-185$. 
Ders., Das Zeitalter der Tyranneien (Mai 1939), in: Joachim Stark (Hg.), Über Deutschland und den Nationalsozialismus. Frühe politische Schriften 1930-1939, Opladen 1993, S. 186-208.

Ders., Demokratische Staaten und totalitäre Staaten (Juni 1939), in: Joachim Stark (Hg.), Über Deutschland und den Nationalsozialismus. Frühe politische Schriften 1930-1939, Opladen 1993, S. 209-241.

Ders., Das Wesen des Totalitarismus (Januar 1954), in: Joachim Stark (Hg.), Über Deutschland und den Nationalsozialismus. Frühe politische Schriften 1930-1939, Opladen 1993, S. 275-293.

Ders., Le Grand Schisme, Paris 1948.

Ders., Les Guerres en Châine, Paris 1951 (dt. Ausg.: Der Permanente Krieg, Frankfurt a. M. 1953).

Ders., L'opium des intellectuels, Paris 1955 (dt. Ausg.: Opium für Intellektuelle oder die Sucht nach Weltanschauung, Köln/Berlin 1957).

Ders., La tragédie algérienne, Paris 1957.

Ders., L'Algérie et la République, Paris 1958.

Ders., La societé industrielle et la guerre, Paris 1958.

Ders., Paix et guerre entre les Nations, Paris 1961 (dt. Ausg.: Frieden und Krieg. Eine Theorie der Staatenwelt, Frankfurt a. M. 1963).

Ders., Dix-huit leçons sur la societé, Paris 1962 (dt. Ausg.: Die industrielle Gesellschaft, Frankfurt a. M. 1964).

Ders., Essai sur les libertés, Paris 1965 (dt. Ausg.: Über die Freiheiten. Essay, Stuttgart 1981).

Ders., Démocratie et totalitarisme, Paris 1965 (dt. Ausg.: Demokratie und Totalitarismus, Hamburg 1970).

Ders., La Révolution introuvable. Réflexions sur la Révolution de Mai, Paris 1968.

Ders., Les Dèsillusions du progrès, Paris 1969 (dt. Ausg.: Fortschritt ohne Ende. Über die Zukunft der Industriegesellschaft, München 1970).

Ders., Maxismes imaginaires. D'une famille à l'autre, Paris 1970 (dt. Ausg.: Die heiligen Familien des Marxismus, Hamburg 1970).

Ders., République impériale, les Etats-Unis dans le monde 1945-1972, Paris 1973 (dt. Ausg.: Die imperiale Republik: die Vereinigten Staaten von Amerika und die übrige Welt seit 1945, Stuttgart 1975).

Ders., Plaidoyer pour l'Europe dècadente, Paris 1977 (dt. Ausg.: Plädoyer für das dekadente Europa, Berlin/Frankfurt a. M. 1978).

Ders., Gibt es ein Nazi-Rätsel (1979), in: Joachim Stark (Hg.), Raymond Aron: Über Deutschland und den Nationalsozialismus. Frühe politische Schriften 1930-1939, Opladen 1993, S. 294-320.

Ders., Der engagierte Beobachter, Gespräche mit Jean-Louis Missika und Dominique Wolton, Stuttgart 1983.

Ders., Erkenntnis und Verantwortung. Lebenserinnerungen, München 1985.

Baberowski, Jörg, Der Rote Terror. Die Geschichte des Stalinismus, München 2003, S. 253-256.

Ders./Doering-Manteuffel, Anselm (Hg.), Ordnung durch Terror: Gewaltexzesse und Vernichtung im nationalsozialistischen und im stalinistischen Imperium, Bonn 2007. 
Augstein, Rudolf/Bracher, Karl Dietrich/Nroszat, Martin/Habermas, Jürgen/Fest Joachim C. (Hg.), »Historikerstreit«. Die Dokumentation der Kontroverse um die Einzigartigkeit der nationalsozialistischen Judenvernichtung, 9. Aufl., München 1995.

Bachmann, Dieter, Ein Bewohner des Zwischenlands. François Bondy, Lebensbild im 84. Jahr, in: Schweizer Zeitschrift DU 10 (1998), S. 50-57.

Backes, Uwe/Jesse, Eckhard (Hg.), Totalitarismus und Totalitarismusforschung. Zur Renaissance einer langen tabuisierten Konzeption, in: Dies. (Hg.) Jahrbuch Extremismus und Demokratie, Bonn/Berlin 1992, S. 7-27.

Dies., Totalitarismus - Extremismus - Terrorismus. Ein Literaturführer und Wegweiser im Lichte deutscher Erfahrung, 2., aktual. und erweit. Aufl., Opladen 1985.

Badstübner, Rolf, Die sowjetische Deutschlandpolitik im Licht neuer Quellen, in: Wilfried Loth (Hg.), Die deutsche Frage in der Nachkriegszeit, Berlin 1994, S. 102-135.

Bailey, George/Kondraschow, Sergej A./Murphy, David E., Die unsichtbare Front. Der Krieg der Geheimdienste im geteilten Berlin, Berlin 1997.

Bald, Detlef, Hiroshima, 6. August 1945. Die nukleare Bedrohung, München 1999.

Beckerath, Erwin von, Wesen und Werden des fascistischen Staates, Berlin 1927.

Ders., Fascismus und Bolschewismus, in: Volk und Reich der Deutschen, Bd. 3, Berlin 1929.

Bendix, Reinhard, Herrschaft und Industriearbeit. Untersuchungen über Liberalismus und Autokratie in der Geschichte der Industrialisierung, Frankfurt a. M. 1960.

Benhabib, Seyla, Hannah Arendt. Die melancholische Denkerin der Moderne. Aus dem Amerik. von Karin Wördemann. Mit einem Nachwort von Otto Kallscheuer, Hamburg 1998.

Benz, Wolfgang, Potsdam 1945. Besatzungsherrschaft und Neuaufbau im Vier-ZonenDeutschland, München 1986.

Ders., Die Gründung der Bundesrepublik. Von der Bizone zum souveränen Staat, 5., überarb. und erweit. Aufl., München 1999.

Berberova, Nina, Die Affäre Krawtschenko. Aus dem Französischen von Bettina Klingler, Hildesheim 1991.

Berlin, Isaiah, Karl Marx. His Life and Environment, London 1939.

Bettelheim, Bruno, Individuelles und Massenverhalten, in: Ders, Erziehung zum Überleben. Zur Psychologie der Extremsituation, Stuttgart 1980, S. 58-95 (amerik. Ausg.: Individual and Mass Behaviour in Extreme Situations, in: Politics, Bd. 1, Nr. 7, August 1944, S. 199-209).

Betz, Albrecht, »Renegaten« im Exil. Münzenberg, Sperber und Koestler im Paris der dreißiger Jahre, in: Tania Schlie/Simone Roche (Hg.), Willi Münzenberg (18891940). Ein deutscher Kommunist im Spannungsfeld zwischen Stalinismus und Antifaschismus, Frankfurt a. M. u. a. 1995, S. 161-172.

Beyme, Klaus von, Totalitarismus - zur Renaissance eines Begriffes nach dem Ende der kommunistischen Regime, in: Achim Siegel (Hg.), Totalitarismustheorien nach dem Ende des Kommunismus, Köln/Weimar 1998, S. 23-36.

Bloom, Alexander, Prodigal Sons, New York Intellectuals and their World, New York 1986.

Bödecker, Birgit, Amerikanische Zeitschriften in deutscher Sprache 1945-1952. Ein Beitrag zur Literatur und Publizistik im Nachkriegsdeutschland, Frankfurt a. M. 1993. 
Boll, Bernd, Generalfeldmarschall Erich von Lewinski, gen. von Manstein, in: Gerd R. Ueberschär (Hg.), Hitlers militärische Elite, Bd. 2: Vom Kriegsbeginn bis zum Weltkriegsende, Darmstadt 1998, S. 143-152.

Bondy, François, Aus nächster Ferne. Berichte eines Literaten in Paris, München 1970.

Ders. (Hg.), So sehen sie Deutschland. Staatsmänner, Schriftsteller und Publizisten aus Ost und West nehmen Stellung, 2. Aufl., Stuttgart 1970.

Ders., Der Rest ist Schreiben. Schriftsteller als Aktivisten, Aufklärer und Rebellen, Wien 1972.

Ders./Abelein, Manfred, Deutschland und Frankreich. Geschichte einer wechselvollen Beziehung, Düsseldorf/Wien 1973.

Ders., Der Nachkrieg muss kein Vorkrieg sein. Europäische Orientierungen, Zürich/ Köln 1985.

Ders., Pfade der Neugier. Porträts, Zürich 1988.

Ders., Polen ist meine schönste Erinnerung an Paris. Ein Gespräch mit Anna Bikont, in: Schweizer Zeitschrift DU 10 (1998), S. 59-63.

Ders., Gespräch, in: 3Sat-Sendung »Kulturzeit« vom 26. Juni 2000.

Borkenau, Franz, Zur Soziologie des Faschismus, in: Archiv für Sozialwissenschaft und Sozialpolitik (Tübingen) 68 (1933), H. 5, S. 513-547.

Ders., Der Übergang vom feudalen zum bürgerlichen Weltbild. Studien zur Geschichte der Philosophie der Manufakturperiode, Paris 1934.

Ders., Pareto, London 1936.

Ders., Austria and After, London 1938.

Ders., Rezension vonf. A. Voigt, Unto Caesar, in: The Sociological Review 30 (1938), S. $421-424$.

Ders., The Communist International, London 1938 (amerik. Ausg.: World Communism. A History of the Communist International, New York 1938).

Ders., The New German Empire, Harmondsworth 1939.

Ders., The Totalitarian Enemy, London 1940.

Ders., Drei Abhandlungen zur deutschen Geschichte, Frankfurt a. M. 1947.

Ders., Die Revolution der Manager, in: Merkur 3 (1949), H. 5, S. 487-494.

Ders., Das Jahr 1917. Wirklichkeit und Legende der russischen Revolution (Sonderdruck zu Der Monat), Berlin 1952.

Ders., Zur Soziologie des Faschismus, in: Ernst Nolte (Hg.), Theorien über den Faschismus, Köln 1967, S. 156-181 (Erstveröffent.: Archiv für Sozialwissenschaft und Sozialpolitik 68 [1933]), H. 5, S. 513-547).

Ders., Ende und Anfang. Von den Generationen der Hochkulturen und von der Entstehung des Abendlandes. Herausgegeben und eingeführt von Richard Löwenthal, Stuttgart 1984.

Ders., Kampfplatz Spanien. Politische und soziale Konflikte im Spanischen Bürgerkrieg, Stuttgart 1986 (engl. Originalausg.: The Spanish Cockpit, London 1938).

Bosshart, David, Politische Intellektualität und totalitäre Erfahrung: Hauptströmungen der französischen Totalitarismuskritik, Berlin 1992.

Bowker, Gordon, George Orwell, London 2003.

Bracher, Karl Dietrich, Stufen totalitärer Machtergreifung: Die Befestigung der nationalsozialistischen Herrschaft 1933/34, in: VfZ 4 (1956), S. 30-42. 
Ders., Der umstrittene Totalitarismus: Erfahrung und Aktualität, in: Ders., Zeitgeschichtliche Kontroversen. Um Faschismus, Totalitarismus, Demokratie, München 1976, S. 33-61.

Ders., Die totalitäre Erfahrung, München 1987.

Ders./Sauer, Wolfgang/Schulz, Gerhard, Die nationalsozialistische Machtergreifung. Studien zur Errichtung des totalitären Herrschaftssystems in Deutschland 1933/34, Köln/Opladen 1960.

Brant, Stefan, Der Aufstand - Vorgeschichte, Geschichte und Deutung des 17. Juni 1953, Stuttgart 1954.

Braun, Jürgen, Stiller Sieg eines Begriffes, in: Das Parlament vom 11./18. November 1994, 44. Jg., Nr. 45/46, S. 1.

Bredow, Wilfried von, Die Vereinten Nationen, in: Hamburger Institut für Sozialforschung (Hg.), 200 Tage und 1 Jahrhundert: Gewalt und Destruktivität im Spiegel des Jahres 1945, Hamburg 1995, S. 167-183.

Breuer, Stefan, Die radikale Rechte in Deutschland 1871-1945. Eine politische Ideengeschichte, Stuttgart 2010.

Ders., Anatomie der konservativen Revolution, Darmstadt 1993.

Breunig, Werner, Berlin-Blockade, in: Wolfgang Benz (Hg.), Deutschland unter alliierter Besatzung: 1945-1949/55, Berlin 1999, S. 330-333.

Brochhagen, Ulrich, Nach Nürnberg. Vergangenheitsbewältigung und Westintegration in der Ära Adenauer, Hamburg 1994.

Broszat, Martin, Der Nationalsozialismus. Weltanschauung, Programmatik und Wirklichkeit, Hannover 1960.

Ders., »Holocaust « und die Geschichtswissenschaft, in: Vierteljahreshefte für Zeitgeschichte 27 (1979), S. 285-298.

Ders., Referat auf dem vom Institut für Zeitgeschichte am 24. November 1978 veranstalteten öffentlichen Kolloquium zu dem Thema »Totalitarismus und Faschismus. Eine wissenschaftliche und politische Begriffskontroverse«, in: Institut für Zeitgeschichte (Hg.), Totalitarismus und Faschismus. Eine wissenschaftliche und politische Begriffskontroverse, München 1980, S. 32-38.

Ders., Der Staat Hitlers. Grundlegung und Entwicklung seiner inneren Verfassung, 14. Aufl., München 1995.

Brünneck, Alexander, Politische Justiz gegen Kommunisten in der Bundesrepublik Deutschland 1949-1969, Frankfurt a. M. 1978.

Brzezinski, Zbigniew K., The Permanent Purge. Politics in Soviet Totalitarianism, Cambridge (Mass) 1956.

Ders./Huntington, Samuel P., Political Power: USA/USSR, London 1964 (dt. Ausg.: Politische Macht. USA/UdSSR, Köln/Berlin 1966).

Buber Agassi, Judith, Margarete Buber-Neumann. Ein biographischer Essay, in: Janine Platten/Dies. (Hg.), Margarete Buber-Neumann. Plädoyer für Freiheit und Menschlichkeit. Vorträge aus 35 Jahren, Berlin 2000, S. 10-30.

Buber-Neumann, Margarete, Milena, Kafkas Freundin, München 1963.

Dies., Von Potsdam nach Moskau. Stationen eines Irrweges, Köln-Lövenich 1981 (dt. Ausg.: Stuttgart 1957).

Dies., Als Gefangene bei Stalin und Hitler. Eine Welt im Dunkeln, Herford 1985 (dt. Ausg.: München 1949). 
Dies., Als Gefangene bei Stalin und Hitler (undatierter Vortrag), in: Janine Platten/ Judith Buber Agassi (Hg.), Margarete Buber-Neumann. Plädoyer für Freiheit und Menschlichkeit. Vorträge aus 35 Jahren, Berlin 2000, S. 110-116.

Dies., Die politische Bedeutung des Krawtschenko-Prozesses, in: Janine Platten/Judith Buber Agassi (Hg.), Margarete Buber-Neumann. Pädoyer für Freiheit und Menschlichkeit. Vorträge aus 35 Jahren, Berlin 2000, S. 174-178.

Dies., Kommunismus und moralische Integrität (offener Brief) in: Janine Platten/ Judith Buber Agassi (Hg.), Margarete Buber-Neumann. Pädoyer für Freiheit und Menschlichkeit. Vorträge aus 35 Jahren, Berlin 2000, S. 178-181.

Buchheim, Hans, Das Dritte Reich. Grundlagen und politische Entwicklung, München 1958.

Ders., Totalitäre Herrschaft. Wesen und Merkmale, 2. Aufl., München 1962.

Ders./Broszat, Martin/Jacobsen, Hans-Adolf/Krausnick, Helmut, Anatomie des SSStaates, 2 Bde, Olten/Freiburg i. Br. 1965.

Buchstein, Hubertus, Politikwissenschaft und Demokratie. Wissenschaftskonzeption und Demokratietheorie sozialdemokratischer Nachkriegspolitologen in Berlin, Baden-Baden 1992.

Buckard, Christian, Koestler, Arthur, Ein extremes Leben. 1905-1983, München 2004.

Burnham, James, The Struggle for the World, New York 1947 (dt. Ausg.: Die Strategie des Kalten Krieges, Stuttgart 1950).

Ders., Das Regime der Manager, Stuttgart 1948 (amerik. Ausg.: The Managerial Revolution, New York 1941).

Ders., Die Machiavellisten. Verteidiger der Freiheit, München 1949.

Ders., The Coming Defeat of Communism, New York 1950 (dt. Ausg.: Die Strategie des kalten Krieges, Stuttgart 1950).

Buscher, Frank M., The U. S. War Crimes Trial Programm in Germany, 1946-1955, New York/Westport/London 1989.

Busse, Mark-Christian von, Faszination und Desillusionierung. Stalinismusbilder von sympathisierenden und abtrünnigen Intellektuellen, Pfaffenweiler 2000.

Campesino, El (d. i. Valentin Gonzales), Die grosse Illusion. Von Madrid nach Moskau, Köln 1951.

Carlton (Hg.), Richard K., Forced Labor in the »People's Democracies«, New York 1955.

Carr, Edward Hallett, Karl Marx, A Study in Fanaticism, London 1935.

Cesarani, David, Koestler, Arthur: The Homeless Mind, London 1999.

Ciliga, Antè, The Russian Enigma, London 1940 (dt. Ausg.: Im Land der verwirrenden Lüge. Zehn Jahre hinter dem Eisernen Vorhang, Köln 1953; frz. Ausg.: Au pays du grand mensonge, Paris 1938).

Clay, Lucius D., Entscheidung in Deutschland, Frankfurt a. M. 1950.

Cohn, Norman, The Pursuit of the Millennium, London 1957 (dt. Ausg.: Das Ringen um das Tausendjährige Reich. Revolutionärer Messianismus im Mittelalter und sein Fortleben in den modernen totalitären Bewegungen, Bern 1961).

Coleman, Peter, The Liberal Conspiracy. The Congress for Cultural Freedom and the Struggle for the Mind of Postwar Europe, New York/London 1989.

Cooney, Terry A., The Rise of the New York Intellectual. Partisan Review and its Circle, 1934-1945, Madison 1986.

Corbin-Schuffels, Anne-Marie, Eine Revanche im Kalten Krieg?, in: Exilforschung. Internationales Jahrbuch 15 (1997): Exil und Widerstand (Hg. im Auftrag der Ge- 
sellschaft für Exilforschung von Claus-Dieter Krohn u. a. unter Mitarbeit von Gerhard Paul, München 1997, S. 255-268.

Courtois, Stéphane, Die Verbrechen des Kommunismus, in: Ders. u. a., Das Schwarzbuch des Kommunismus. Unterdrückung, Verbrechen und Terror, München/Zürich 1998, S. 11-43.

Ders./Werth, Nicolas/Banné, Jean-Louis/Paczkowski, Andrezej/Bartosek, Karel/Margolin, Jean-Louis, Das Schwarzbuch des Kommunismus. Unterdrückung, Verbrechen und Terror, München/Zürich 1998.

Crick, Bernhard, George Orwell. Ein Leben. Aus dem Englischen von Friedrich Polakovics unter Mitwirkung von Harald Raykowski, Frankfurt a. M. 1984.

Crossmann, Richard H. S. (Hg.), Ein Gott der keiner war. Arthur Koestler, Ignazio Silone, Richard Wright, André Gide, Louis Fischer, Stephen Spender schildern ihren Weg zum Kommunismus und ihre Abkehr. Mit einem Vorwort von Richard Crossmann und einem Nachwort von Franz Borkenau, Konstanz/Zürich/Wien 1950 (engl. Ausg.: The God that Failed, London 1949).

Dallin, David/Nicolaevsky, Boris, Forced Labor in Soviet Russia, New Haven 1947 (dt. Ausg.: Arbeiter oder Ausgebeutete. Das System der Arbeitslager in Sowjetrußland, hg. von »Die Neue Zeitung«, München 1948).

Davies, Joseph, Mission to Moscow, New York 1941.

Decke, Ludwig, Ungleiche Weggefährten: Hannah Arendt, Melvin Lasky und der Antitotalitarismus im kulturellen Kalten Krieg, in: Yfaat Weiss (Hg.), Jahrbuch des Dubnow Instituts/Dubnow Institute Yearbook 17 (2018), S. 117-144.

Deutsch, Karl W., Risse im Monolith: Möglichkeiten und Arten der Desintegration in totalitären Systemen, in: Bruno Seidel/Siegfried Jenkner (Hg.), Wege der Totalitarismusforschung, Darmstadt 1968, S. 197-227.

Deutscher Bundestag (Hg.), Materialien der Enquete-Kommission »Aufarbeitung von Geschichte und Folgen der SED-Diktatur in Deutschland « (12. Wahlperiode des Deutschen Bundestages), 9 Bde. in 18 Teilbdn., Baden-Baden/Frankfurt a. M. 1995.

Die Tscheka. Russische Hilferufe an das Weltgewissen, Berlin 1922.

Diner, Dan, Das Jahrhundert verstehen. Eine universalhistorische Deutung, Frankfurt a. M. 2000.

Dierks, Walter, Nürnberg und die Geschichte 1 (1946), H. 1, S. 3-5.

Ders., Das Wort Sozialismus, in: Frankfurter Hefte 1 (1946), H. 7, S. 628-643.

Doering-Manteuffel. Anselm, Westernisierung. Politisch-ideeller und gesellschaftlicher Wandel in der Bundesrepublik bis zum Ende der 6oer Jahre, in: Axel Schildt u.a. (Hg.), Dynamische Zeiten. Die 6oer Jahre in den beiden deutschen Gesellschaften, Hamburg 2000, S. 311-341.

Ders., Amerikanisierung und Westernisierung, Version: 2.0, in: Docupedia-Zeitgeschichte, 19.08.2019.

Ders., Die deutsche Geschichte in den Zeitbögen des 20. Jahrhunderts, in: Vierteljahreshefte für Zeitgeschichte 62 (2014), S. 321-348.

Ders., Wie westlich sind die Deutschen?, Göttingen 1999.

Ders./Leonhard, Jörn, Liberalismus im 20. Jahrhundert, Stuttgart 2015.

Dorman, Joseph, Arguing the World. The New York Intellectuals in their Own Words, New York 2000. 
Draht, Martin, Totalitarismus in der Volksdemokratie, Einleitung in: Ernst Richert, Macht ohne Mandat. Der Staatsapparat in der Sowjetischen Besatzungszone Deutschlands, Köln 1958, S. IX-XXXIV.

Dubiel, Helmut/Söllner, Alfons, Die Nationalsozialismusforschung des Instituts für Sozialforschung - ihre wissenschaftliche Stellung und ihre gegenwärtige Bedeutung, in: Dies. (Hg.), Wirtschaft, Recht und Staat im Nationalsozialismus, Frankfurt a. M. 1984, S. 7-31.

Dülffer, Jost, Jalta, 4. Februar 1945. Der Zweite Weltkrieg und die Entstehung der bipolaren Welt, 2. Aufl., München 1999.

Dutschke, Rudi/Wilke, Manfred (Hg.), Die Sowjetunion, Solschenizyn und die westliche Linke. Unter Mitarbeit von Reinhard Crusius, Reinbek bei Hamburg 1975.

Eberan, Barbro, Die Debatte um die Schuldfrage 1945-1949, München 1983.

Erd, Rainer (Hg.), Reform und Resignation. Gespräche über Franz L. Neumann, Frankfurt a. M. 1985.

Fischer, Ruth, Stalin and German Communism, New York 1948 (dt. Ausg.: Stalin und der deutsche Kommunismus: Der Übergang zur Konterrevolution, Frankfurt a. M. o. J.

Fitzpatrick, Sheila/Geyer, Michael (Hg.), Beyond Totalitarianism. Stalinism and Nazism Compared, Cambridge 2009.

Ford, Guy Stanton (Hg.), Dictatorship in the Modern World, Minneapolis (Minn) 1935.

Forsthoff, Ernst, Der totale Staat, Hamburg 1933.

Foschepoth, Josef (Hg.), Kalter Krieg und Deutsche Frage. Deutschland im Widerstreit der Mächte 1945-1952, Göttingen/Zürich 1985, S. 11-31.

Fraenkel, Ernst, Der Doppelstaat. Recht und Justiz im »Dritten Reich«, Frankfurt a. M. 1974 (amerik. Ausg.: The Dual State. A Contribution to the Theory of Dictatorship, New York 1941).

Ders., Gedenkrede auf Franz L. Neumann, in: Ders., Reformismus und Pluralismus. Materialien zu einer ungeschriebenen politischen Autobiographie. Zusammengestellt und hg. von Falk Esche und Frank Grube. Hamburg 1973, S. 168-179.

Franke, Anselm/Ghouse, Nida/Guevara, Paz/Majaca, Antonia, Parapolitics. Cultural Freedom and the Cold War, Sternberg Press 2011.

Frei, Norbert, Vergangenheitspolitik. Die Anfänge der Bundesrepublik und die NSVergangenheit, München 1999.

Ders., Von deutscher Erfindungskraft oder: Die Kollektivschuldthese in der Nachkriegszeit, in: Rechtshistorisches Journal 16 (1997), S. 621-634.

Friedmann, Friedrich Georg, Hannah Arendt - Eine deutsche Jüdin im Zeitalter des Totalitarismus, München/Zürich 1985.

Friedrich, Carl J., The Unique Character of Totalitarian Society, in: Ders. (Hg.), Totalitarianism. Proceeding of a Conference held at the American Academy of Arts and Sciences, March 1953, Cambridge (Mass) 1954, S. 47-60

Ders./Brzezinski, Zbigniew K., Totalitarian Dictatorship and Autocracy, Cambridge (Mass) 1956 (dt. Ausg.: Carl J. Friedrich, unter Mitarbeit von Zbigniew K. Brzezinski, Totalitäre Diktatur, Stuttgart 1957).

Friedrich, Jörg, Die kalte Amnestie. NS-Täter in der Bundesrepublik, Frankfurt a. M. 1984.

Frießner, Hans, Verratene Schlachten. Die Tragödie der deutschen Wehrmacht in Ungarn und Rumänien, Hamburg 1956. 
Funke, Hajo, Gott Macht Amerika. Ideologie, Religion und Politik der US-amerikanischen Rechten, Berlin 2006.

Funke, Martin, Totalitarismus. Ein Studien-Reader zur Herrschaftsanalyse moderner Diktaturen, Düsseldorf 1978.

Furet, François, Das Ende der Illusion. Der Kommunismus im 20. Jahrhundert, München 1996.

Garner, Curt, Der öffentliche Dienst in den 5oer-Jahren: Politische Weichenstellung und ihre sozialgeschichtlichen Folgen, in: Axel Schildt/Arnold Sywottek (Hg.), Modernisierung im Wiederaufbau: die westdeutsche Gesellschaft der 5oer-Jahre, Bonn 1993, S. 759-790.

Gassert, Phillip, Die Bundesrepublik, Europa und der Westen. Zu Verwestlichung, Demokratisierung und einigen komparatistischen Defiziten der zeithistorischen Forschung, in: Jörg Baberowski/Eckart Conze/Phillip Gassert/Martin Sabrow, Geschichte ist immer Gegenwart. Vier Thesen zur Zeitgeschichte, Stuttgart/München 2001, S. 67-89.

Ders., Amerikanismus, Antiamerikanismus, Amerikanisierung. Neue Literatur zur Sozial-, Wirtschafts- und Kulturgeschichte in Deutschland und Europa, in: Archiv für Sozialgeschichte 39 (1999), S. 531-561.Gehring, Hansjörg, Amerikanische Literaturpolitik in Deutschland 1945-1953. Ein Aspekt des Re-Education-Programms, Stuttgart 1976.

Geiss, Imanuel, Der Hysterikerstreit. Ein unpolemischer Essay, Bonn 1992.

Ders., Die Totalitarismen unseres Jahrhunderts, in: Eckhard Jesse (Hg.), Totalitarismus im 20. Jahrhundert. Eine Bilanz der internationalen Forschung, Bonn 1996, S. $160-175$.

Gerhardt, Uta, Soziologie der Stunde Null. Zur Gesellschaftskonzeption des amerikanischen Besatzungsregimes 1944-1945/1946, Frankfurt a. M. 2005.

Gess, Brigitte, Liberales Denken und intellektuelles Engagement. Die Grundzüge der philosophisch-politischen Reflexionen Raymond Arons, München 1988.

Dies., Raymond Aron, in: Karl Graf Ballestrem/Henning Ottmann (Hg.), Politische Philosophie des 20. Jahrhunderts, München 1990, S. 33-45.

Glaser, Georg K., Geheimnis und Gewalt. Ein Bericht, Stuttgart/Hamburg 1953.

Glaser, Hermann, Kulturgeschichte der Bundesrepublik Deutschland, 3 Bde., München $1985 \mathrm{ff}$.

Gleason, Abbott, Totalitarianism. The Inner History of the Cold War, New York 1995.

Glucksmann, André, La cuisinière et le mangeur d'hommes, Paris 1974 (dt. Ausg.: Köchin und Menschenfresser. Über die Beziehung zwischen Staat, Marxismus und Konzentrationslager, Berlin 1976).

Goebbels, Joseph, Signale der neuen Zeit, 3. Aufl., München 1937, S. 285 f.

Goldstein, Sandra, Intellektuelle Utopien. Arthur Koestler und der Zionismus, in: Jakob Hessing und Alfred Bodenheimer (Hg.), Jüdischer Almanach 1998/5758 des Leo Baeck Instituts. Hg. von Jakob Hessing und Alfred Bodenheimer, Frankfurt a. M. 1997, S. 158-169.

Görtemaker, Manfred, Geschichte der Bundesrepublik Deutschland. Von der Gründung bis zur Gegenwart, München 1999.

Graml, Hermann, Strukturen und Motive alliierter Besatzungspolitik in Deutschland, in: Wolfgang Benz (Hg.), Deutschland unter alliierter Besatzung: 1945-1949/55, Berlin 1999, S. 21-32. 
Ders., Zwischen Jalta und Potsdam, in: Vierteljahreshefte für Zeitgeschichte 24 (1976), S. $308-316$.

Grebing, Helga, Der Nationalsozialismus, München 1959.

Dies., Konservative gegen die Demokratie. Konservative Kritik an der Demokratie in der Bundesrepublik nach 1945, Frankfurt a. M. 1971.

Greiffenhagen, Martin/Kühnl, Reinhard/Müller, Johann Baptist, Totalitarismus. Zur Problematik eines politischen Begriffs, München 1972.

Greiner, Bernd, Die Morgenthau-Legende. Zur Geschichte eines umstrittenen Plans, Hamburg 1995.

Ders., Remigranten über den Nürnberger Prozess, in: Claus-Dieter Krohn/Axel Schildt (Hg.), Zwischen den Stühlen? Remigranten und Remigration in der deutschen Medienöffentlichkeit der Nachkriegszeit, Hamburg 2002, S. 145-160.

Grémion, Pierre, Intelligence de l'Anticommunisme. Le Congrès pour la liberté de la culture à Paris 1950-1975, Paris 1995.

Greven, Michael Th. , Politisches Denken in Deutschland nach 1945. Erfahrungen und Umgang mit der Kontingenz in der unmittelbaren Nachkriegszeit. Opladen/Farmington Hills 2007.

Ders., Die politische Gesellschaft. Kontingenz und Dezision als Probleme des Regierens und der Demokratie, Opladen 1999.

Ders., Die Allgegenwart des Politischen und die Randständigkeit der Politikwissenschaft, in: Claus Leggewie (Hg.), Wozu Politikwissenschaft? Über das Neue in der Politik, Darmstadt 1994, S. 285-296.

Gross, Babette, Willi Münzenberg. Eine politische Biographie mit einem Vorwort von Arthur Koestler, Stuttgart 1969.

Grunenberg, Antonia, Antifaschismus - ein deutscher Mythos, Reinbek bei Hamburg 1993.

Dies., (Hg.), Totalitäre Herrschaft und republikanische Demokratie. Fünfzig Jahre The Origins of Totalitarianism von Hannah Arendt. Unter Mitarbeit von Stefan Ahrens und Bettina Koch, Frankfurt a. M. 2003.

Guderian, Heinz, Erinnerungen eines Soldaten, Heidelberg 1950.

Gurian, Waldemar, Fascismus und Bolschewismus, in: Das Heilige Feuer 15 (1927/28).

Ders., Der Bolschewismus. Einführung in Geschichte und Lehre, Freiburg i. Br. 1931.

Ders., Nationalsozialismus und Bolschewismus - ein Vergleich, in: Heinz Hürten (Bearb.), Deutsche Briefe. Ein Blatt der katholischen Emigration. Bd. 1, Mainz 1969, S. 305 f. und S. $377-381$.

Gurland, A[rkadij] R. L., Einleitung, in: Max G. Lange, Totalitäre Erziehung. Das Erziehungssystem der Sowjetzone Deutschlands, Frankfurt a. M. 1954, S. VIIIXXXVI.

Haasis, Hellmut von (Hg.), Walter G. Krivitsky: Ich war Stalins Agent, Grafenau-Döffingen 1990.

Habe, Hans, Im Jahre Null, vom Autor revidierte und erweiterte Ausg., München 1977.

Hacke, Jens, Existenzkrise der Demokratie. Zur politischen Theorie des Liberalismus in der Zwischenkriegszeit, Berlin ${ }^{2} 2018$.

Halder, Franz, Hitler als Feldherr. Der ehemalige Chef des Generalstabes berichtet die Wahrheit, Tübingen 1949.

Hamilton, Iain, Koestler. A Biography, New York 1982. 
Hankel, Gerd/Stuby, Gerhard (Hg.), Strafgerichte gegen Menschheitsverbrechen. Zum Völkerstrafrecht 50 Jahre nach den Nürnberger Prozessen, Hamburg 1995.

Harper, Samuel N., Civic Training in Soviet Russia, Chicago 1929.

Harpprecht, Klaus, Wir wollten Weltluft. Unzeitgemäße Anmerkungen über den CIA, den Monat und den »Kongress für die Freiheit der Kultur«, in: Die Zeit vom 21. Juni 2000, S. 42.

Ders., Die geistige Résistance nach 1945, in: Die Neue Gesellschaft/Frankfurter Hefte 48 (2001), S. 314-317.

Hartmann, Anne/Eggeling, Wolfram, Sowjetische Präsenz im kulturellen Leben der SBZ und frühen DDR 1945-1953, Berlin 1998.

Hayes, Carlton J. H., Der Totalitarismus als etwas Neues in der Geschichte der westlichen Kultur, in: Bruno Seidel/Siegfried Jenkner (Hg.), Wege der TotalitarismusForschung, Darmstadt 1968, S. 86-100 (engl. Ausg.: The Novelty of Totalitarianism in the History of Western Civilisation, in: Symposium on the Totalitarian State. From the Standpoints of History, Political Science, Economics and Sociology, Nov. 17, 1939. Proceedings of the American Philosophical Society, Bd 82, 1940, Nr. 1, Philadelphia 1940, S. 91-102).

Henke, Klaus-Dietmar, Die Trennung vom Nationalsozialismus. Selbstzerstörung, politische Säuberung, »Entnazifizierung«, Strafverfolgung, in: Ders./Hans Woller (Hg.), Politische Säuberung in Europa. Die Abrechnung mit Faschismus und Kollaboration nach dem Zweiten Weltkrieg, München 1991, S. 21-83.

Herbert, Ulrich, Wer waren die Nationalsozialisten?, München 2021.

Ders., Deutsche Eliten nach Hitler, in: Mittelweg 36, 8 (1999), H. 3, S. 66-82.

Ders., Vernichtungspolitik. Neue Antworten und Fragen zur Geschichte des »Holocaust«, in: Ders. (Hg.), Nationalsozialistische Vernichtungspolitik 1939-1945. Neue Forschungen und Kontroversen, Frankfurt a. M. 1998, S. 9-66.

Ders., Best. Biographische Studien über Radikalismus, Weltanschauung und Vernunft. 1903-1989, Bonn 1996.

Ders., Zweierlei Bewältigung, in: Ders./Olaf Groehler, Zweierlei Bewältigung: Vier Beiträge über den Umgang mit der NS-Vergangenheit in den beiden deutschen Staaten, Hamburg 1992, S. 7-29.

Ders./ Schildt, Axel, Kriegsende in Europa, in: Dies. (Hg.), Kriegsende in Europa: vom Beginn des deutschen Machtzerfalls bis zur Stabilisierung der Nachkriegsordnung 1944-1948, Essen 1998, S. 7-34.

Hermand, Jost, Kultur im Wiederaufbau. Die Bundesrepublik 1945-1965, Frankfurt a. M./Berlin 1989.

Herz, Dietmar, Der Begriff der "politischen Religionen« im Denken Eric Voegelins, in: Hans Maier (Hg.), >Totalitarismus und >politische Religionen<. Konzepte des Diktaturvergleichs, Paderborn u. a. 1996, S. 191-209.

Heuer, Wolfgang, Hannah Arendt. Mit Selbstzeugnissen und Bilddokumenten, Reinbek bei Hamburg 1987.

Ders., Citizen. Persönliche Integrität und politisches Handeln. Eine Rekonstruktion des politischen Humanismus Hannah Arendts, Berlin 1992.

Heusinger, Adolf, Befehl im Widerstreit. Schicksalsstunden der deutschen Armee. 1923-1945, Tübingen 1950.

Hilberg, Raul/Söllner, Alfons, Das Schweigen zum Sprechen bringen. Ein Gespräch über Franz Neumann und die Entwicklung der Holocaust-Forschung, in: Dan 
Diner (Hg.), Zivilisationsbruch. Denken nach Auschwitz, Frankfurt a. M. 1988, S. $175-200$.

Hilferding, Rudolf, The Modern Totalitarian State, in: Modern Review I (1947), S. 597605.

Hochgeschwender, Michael, Konservatismus in der Nachkriegszeit. Entwicklungen in den USA und Westdeutschland, in: Vierteljahreshefte für Zeitgeschichte 68 (2020), H. 4, S. 629-641.

Ders., Der Verlust des konservativen Denkens. Eine Facette der bundesdeutschen Westernisierung 1950-1980, in: Axel Schildt (Hg.), Von draußen. Ausländische intellektuelle Einflüsse in der Bundesrepublik bis 1990, Göttingen 2016, S. 149-190.

Ders., Das Ende des Konsenses: Die Reformation des US-amerikanischen conservatism seit den 1960er Jahren, in: comparativ 16 (2006), H. 4, S. 131-166.

Ders., Freiheit in der Offensive? Der Kongreß für kulturelle Freiheit und die Deutschen, München 1998.

Ders., Remigranten im Umfeld der Zeitschrift Der Monat und des Congress for Cultural Freedom (CCF), in: Claus-Dieter Krohn und Axel Schildt (Hg.), Zwischen den Stühlen? Remiganten und Remigration in der deutschen Medienöffentlichkeit der Nachkriegszeit, Hamburg 2002, S. 180-206.

Hoeres, Peter, Gefangen in der analytisch-normativen Westernisierung der Zeitgeschichte. Eine Kritik am Konzept der Zeitbögen, in: Vierteljahreshefte für Zeitgeschichte 63 (2015), H. 3, S. 427-436.

Ders., Außenpolitik und Öffentlichkeit. Massenmedien, Meinungsforschung und Arkanpolitik in den deutsch-amerikanischen Beziehungen von Erhard bis Brandt, München 2013.

Hofer, Walther (Hg.), Der Nationalsozialismus. Dokumente 1933-1945, Frankfurt a. M. 1957.

Holländer, Katharina, An die Kinder. Ein Gespräch mit Lillian Bondy, in: Schweizer Zeitschrift DU 10 (1998), S. 72 f. u. 94.

Hook, Sidney, Out of Step. An unquit Life in the $20^{\text {th }}$ Century, New York 1987.

Howald, Stefan, George Orwell, Reinbek bei Hamburg 1997.

Huber, Ernst Rudolf, Die Totalität des völkischen Staates, in: Die Tat 26 (1934), S. 3042.

Hürten, Heinz, Waldemar Gurian und die Entfaltung des Totalitarismusbegriffs, in: Hans Maier (Hg.), ,Totalitarismus und >politische Religionen<. Konzepte des Diktaturvergleichs, Paderborn u. a. 1996, S. 59-70.

Ders., Modernitätskritik und Totalitarismustheorie im Frühwerk Waldemar Gurians, in: Alfons Söllner/Ralf Walkenhaus/Karin Wieland (Hg.), Totalitarismus - Eine Ideengeschichte des 20. Jahrhunderts, Berlin 1997, S. 27-34.

Hurwitz, Harold, Der heimliche Leser. Beiträge zur Soziologie des geistigen Widerstandes, Köln/Berlin 1966.

Ders., Die Stunde Null der deutschen Presse. Die amerikanische Pressepolitik in Deutschland 1945-1949, Köln 1972.

Huttner, Markus, Totalitarismus und säkulare Religionen. Zur Frühgeschichte totalitarismuskritischer Begriffs- und Theoriebildung in Großbritannien, Bonn 1999.

Institut für Zeitgeschichte (Hg.), Totalitarismus und Faschismus. Eine wissenschaftliche und politische Begriffskontroverse, München 1980. 
Intelmann, Peter, Chancen und Dilemma des politischen Reformismus, Baden-Baden 1996.

Internationaler Militärgerichtshof Nürnberg (Hg.), Der Prozeß gegen die Hauptkriegsverbrecher vor dem Internationalen Militärgerichtshof Nürnberg, 14. November 1945-1. Oktober 1946. 42 Bde., Nürnberg 1947-1949.

Isaacson, Walter/Thomas, Evan, The Wise Men. Six Friends and the World They Made. Acheson, Bohlen, Harriman, Kennan, Lovett, McCloy, New York u. a. 1986.

Jackson, Robert H., Dokumente der Zeit. Grundlegende Rede vorgetragen im Namen der Vereinigten Staaten von Amerika von dems. - Hauptanklagevertreter der USA beim Internationalen Militärgerichtshof zu Nürnberg, Frankfurt a. M. 1946.

Jänicke, Martin, Der dritte Weg. Die antistalinistische Opposition gegen Ulbricht seit 1953, Köln 1964.

Ders., Totalitäre Herrschaft. Anatomie eines politischen Begriffes, Berlin (West) 1971.

Jakowlew, B., Konzentrazionnye lageri SSSR. Hg. v. Institut zur Erforschung der Geschichte und Kultur der UdSSR, München 1955.

Jansen, Peter-Erwin u. a. (Hg.), Zwischen Hoffnung und Notwendigkeit. Texte zu Herbert Marcuse, Frankfurt a. M. 1999, S. 7--13.

Ders. (Hg.), Herbert Marcuse, Feinanalysen. Über die Deutschen, mit einer Einleitung von Detlev Claussen, Lüneburg 1998.

Jarausch, Konrad, Die Umkehr. Deutsche Wandlungen 1945-1995, Bonn 2004.

Jaspers, Karl, Die Schuldfrage, in: Ders., Lebensfragen der deutschen Politik, München 1963, S. 36-109.

Jenkner, Siegfried, Entwicklung und Stand der Totalitarismusforschung, in: Politik und Zeitgeschichte, B 31, 1984, S. 16-26.

Jesse, Eckhard, War die DDR totalitär?, in: Aus Politik und Zeitgeschichte, B 40/7. Oktober 1994, S. 12-23.

Ders. (Hg.),Totalitarismus im 20. Jahrhundert. Eine Bilanz der internationalen Forschung, Bonn 1996.

Ders., Die Totalitarismusforschung und ihre Repräsentanten. Konzeptionen von Carl J. Friedrich, Hannah Arendt, Eric Voegelin, Ernst Nolte und Karl Dietrich Bracher, in: Aus Politik und Zeitgeschichte, B 20, 1998, S. 3-18.

Jessen, Ralph, DDR-Geschichte und Totalitarismustheorie, in: Berliner Debatte INITIAL 6 (1995) 4/5, S. 17-24.

Jörke, Dirk/Selk, Veith, Theorien des Populismus zur Einführung, Hamburg 2017.

Johnson, Lock K., Verdeckte Aktionen und die CIA: Amerikas geheime Außenpolitik, in: Wolfgang Krieger (Hg.), Geheimdienste in der Weltgeschichte. Spionage und verdeckte Aktionen von der Antike bis zur Gegenwart, München 2003, S. 260-274.

Jones, William, The Path from Weimar Communism to the Cold War. Franz Borkenau and »The Totalitarian Enemy«, in: Alfons Söllner/Ralf Walkenhaus/Karin Wieland (Hg.), Totalitarismus. Eine Ideengeschichte des 20. Jahrhunderts, Berlin 1997, S. $39-43$.

Kantorowicz, Alfred, Spanisches Kriegstagebuch, Köln 1966.

Kapferer, Norbert, Der Totalitarismusbegriff auf dem Prüfstand. Ideengeschichtliche, komparatistische und politische Aspekte eines umstrittenen Terminus, hg. v. Hannah-Arendt-Institut für Totalitarismusforschung, 2., unveröffentl. Aufl., Dresden 1995. 
Katz, Barry M., Foreign Intelligence. Research and Analysis in the Office of Strategic Services 1942-1945, London 1989.

Kempner, Robert W., Ankläger einer Epoche. Lebenserinnerungen, Frankfurt a. M. 1983.

Kennan, Georgef. (unter dem Pseudonym $" X \lll)$, The Sources of Soviet Conduct, in: Foreign Affairs 25 (1946/47), S. $566 \mathrm{ff}$.

Ders., Memoiren eines Diplomaten. Mit einem Vorwort von Klaus Mehnert, Stuttgart 1968.

Kesselring, Albert, Soldat bis zum letzten Tag, Bonn 1953.

Keßler, Mario, Zwischen Kommunismus und Antikommunismus: Franz Borkenau (1900-1957), in: Ders. (Hg.), Deutsche Historiker im Exil (1933-1945): Ausgewählte Studien, Berlin 2005, S. 169-196.

Ketterle, Margit, Literatur und Politik im Nachkriegsdeutschland der Zeitschrift "Der Monat«1948-1955 (unveröffentl. Magisterarbeit), München 1984.

Kießling, Friedrich, »Westernisierung, Internationalisierung, Bürgerlichkeit? Zu einigen jüngeren Arbeiten der Ideengeschichte der alten Bundesrepublik«, in: Historische Zeitschrift 287 (2008), S. 363-383.

Klein, Peter, in: Ders. (Hg.), Die Einsatzgruppen in der besetzten Sowjetunion 1941/42. Die Tätigkeits- und Lageberichte des Chefs der Sicherheitspolizei und des SD, Berlin 1997, S. 9-28.

Klemperer, Victor, LTI. Notizbuch eines Philologen, Berlin 1947.

Kleßmann, Christoph, Die doppelte Staatsgründung. Deutsche Geschichte 1945-1955, 4., erg. Aufl., Bonn 1986.

Ders., Zwei Staaten, eine Nation. Deutsche Geschichte 1955-1970, Bonn 1988.

Klönne, Arno, Hitlerjugend. Die Jugend und ihre Organisation im Dritten Reich, Hannover/Frankfurt a. M. 1960.

Klotz, Johannes (Hg.), Schlimmer als die Nazis? »Das Schwarzbuch des Kommunismus«, die neue Totalitarismusdebatte und der Geschichtsrevisionismus, Köln 1999.

Knappstein, Karl Heinrich, Die Stunde der Sozialreform, in: Frankfurter Hefte 1 (1946), H. 3, S. 1-3.

Ders., Die versäumte Revolution, in: Die Wandlung 2 (1947), H. 8, S. 663-677.

Koebner, Thomas, Arthur Koestlers Abkehr vom Stalinismus, in: Exilforschung. Ein Internationales Jahrbuch 1 (1983), S. 95-108.

Koestler, Arthur und Cynthia, Auf fremden Plätzen. Bericht über die gemeinsame Zeit. Hg., mit einem Vorwort und einem Epilog versehen von Harold Harris. Übersetzt von Liesl Nürenberger, Wien/München/Zürich 1984.

Koestler, Arthur, Menschenopfer unerhört. Ein Schwarzbuch über Spanien, Paris 1937.

Ders., Spanish Testament, London 1937 (dt. Ausg.: Ein spanisches Testament, Zürich 1938).

Ders., The Gladiators, London 1939 (dt. Ausg.: Die Gladiatoren, Hamburg 1948).

Ders., Scum of the Earth, London 1941.

Ders., Arrival and Departure, London 1943 (dt. Ausg.: Ein Mann springt in die Tiefe, Zürich 1945).

Ders., Der Yogi und der Kommissar. Auseinandersetzungen, Eßlingen a. N. 1950 (engl. Ausg.: The Yogi and the Commissar, London 1945).

Ders., Warum Greueltaten nicht geglaubt werden, in: Ders., Der Yogi und der Kommissar. Auseinandersetzungen, Eßlingen a. N. 1950, S. 138-147. 
Ders., Gottes Thron steht leer, Frankfurt a. M. 1951 (engl. Ausg.: The Age of Longing, London 1951).

Ders., Pfeil ins Blaue. Bericht eines Lebens 1905-1931, Wien/München/Basel 1953 (engl. Ausg.: Arrow in the Blue, London 1952).

Ders., Die Geheimschrift. Bericht eines Lebens, Wien/München/Basel 1955 (engl. Ausg.: The Invisible Writing, London 1954).

Ders, Reflections on Hanging, London 1956.

Ders., Sonnenfinsternis. Roman. Aus dem Engl., Frankfurt a. M./Berlin/Wien 1979 (engl. Ausg.: Darkness at Noon, London 1940; dt. Erstausg.: Stuttgart 1948).

Ders., Als Zeuge der Zeit. Das Abenteuer meines Lebens, Bern/München 1983.

Ders., Autobiographische Schriften. 2 Bde., Bd. 1: Frühe Empörung; Bd. 2: Abschaum der Erde. Aus dem Engl. übertr. v. Franziska Becker und Eduard Thorsch (bzw. Heike Curtze), Berlin/München 1993.

Kogon, Eugen, Gericht und Gewissen, in: Frankfurter Hefte 1 (1946), H. 1, S. 25-37.

Ders., Das Recht auf politischen Irrtum, in: Frankfurter Hefte 2 (1947), H. 7, S. 641-655 (Zitat S. 646).

Ders., Der Weg zu einem Sozialismus der Freiheit in Deutschland, in: Frankfurter Hefte 2 (1947), H. 9, S. 877-896.

Kohn, Hans, Nationalismus. Über die Bedeutung des Nationalismus im Judentum und in der Gegenwart, Wien 1922.

Ders., Sinn und Schicksal der Revolution, Wien 1923.

Ders., Die politische Idee des Judentums, München 1924.

Ders., Eine Geschichte der arabischen nationalen Bewegung, Tel Aviv 1926.

Ders., Geschichte der nationalen Bewegung im Orient, Berlin 1928.

Ders., Über die Geschichte der zionistischen Idee, 2 Bde, Warschau 1929/1930.

Ders., Martin Buber. Sein Werk und seine Zeit. Ein Versuch über Religion und Politik, Hellerau 1930.

Ders., Nationalismus und Imperialismus im Vorderen Orient, Frankfurt a. M. 1931.

Ders., Der Nationalismus in der Sowjetunion, Frankfurt a. M. 1932.

Ders., Communist and Fascist Dictatorship. A Comparative Study, in: Guy Stanton Ford (Hg.), Dictatorship in the Modern World, Minneapolis (MN) 1935, S. 141-160 (dt. Wiederabdr.: Bruno Seidel/Siegfried Jenkner (Hg.), Wege der Totalitarismusforschung, Darmstadt 1968, S. 49-63).

Ders., Revolutions and Dictatorships. Essays in Contemporary, Cambridge (MA) 1941.

Ders., The Totalitarian Philosophy of War, in: Symposium of the Totalitarian State. From the Standpoints of History, Economics and Sociology, Nov. 17, 1939. Proceedings of the American Philosophical Society, Bd. 82 (1940), Nr. 1, Philadelphia 1940, S. $57-72$.

Ders., Prophets and Peoples. Studies in Nineteenth-Century Nationalism, New York 1946 (dt. Übers.: Propheten ihrer Völker. Mill, Michelet, Treitschke, Dostojewski: Studien zur Geschichte des europäischen Nationalismus im 19. Jahrhundert, Bern 1949).

Ders., Die Idee des Nationalismus. Ursprung und Geschichte bis zur Französischen Revolution, Heidelberg 1950 (amerik. Ausg.: The Idea of Nationalism. A Study in its Origins and Background, New York 1944). 
Ders., Das Zwanzigste Jahrhundert. Eine Zwischenbilanz des Westens, Zürich/Wien/ Konstanz 1950 (amerik. Ausg.: The Twentieth Century. A Mid-way Account of the Western World, New York 1949).

Ders., Pan-Slavism, Its History and Ideology, University of Notre Dame Press 1953 (dt. Übers.: Die Slawen und der Westen. Die Geschichte des Panslawismus, Wien 1956.

Ders., Nationalism, its Meaning and History, Princeton 1955 (dt. Ausg.: Von Machiavelli zu Nehru. Zur Problemgeschichte des Nationalismus, Freiburg i. Br. 1964).

Ders., Der schweizerische Nationalgedanke. Eine Studie zum Thema Nationalismus und Freiheit, Zürich 1955.

Ders., American Nationalism. An Interpretative Essay, New York 1957.

Ders., Is the liberal west in decline, London 1957 (dt. Ausg.: Ist die freie Welt zum Untergang verurteilt?, Köln 1959).

Ders., The Mind of Germany, New York 1960 (dt. Ausg.: Wege und Irrwege. Zur Geistesgeschichte des bürgerlichen Deutschland, Düsseldorf 1962).

Ders., The Age of Nationalism: The First Era of Global History, New York 1962.

Ders., Bürger vieler Welten. Ein Leben im Zeitalter der Weltrevolution, Frauenfeld 1965.

Ders./Hugo Bergmann, In Memory of Gustav Landauer, Tel Aviv 1929.

Ders./Robert Weltsch, Zionistische Politik, Mährisch-Ostrau 1927.

Komuth, Horst, Manès Sperber, Arthur Koestler und George Orwell: Der Totalitarismus als Geißel des 20. Jahrhunderts, Würzburg 1987.

Krämer-Badoni, Rudolf, Terror der Anständigen, in: Die Wandlung 2 (1947), H. 5, S. 379-391.

Kraushaar, Wolfgang, Sich aufs Eis wagen. Plädoyer für eine Auseinandersetzung mit der Totalitarismustheorie, in: Mittelweg 36, 2 (1993), H. 2, S. 6-29.

Ders., Die Protest-Chronik 1949-1959. Eine illustrierte Geschichte von Bewegung, Widerstand und Utopie, 4 Bde., Hamburg 1996.

Ders., Spuren eines Paradigmenwechsels. Von der Totalitarismus- zur Faschismustheorie, in: Ders., Linke Geisterfahrer. Denkanstöße für eine antitotalitäre Linke. Mit einer Einleitung von Daniel Cohn-Bendit, Frankfurt a. M. 2001, S. 109-130.

Ders., Sonnenuntergang. Das Verhältnis europäischer Intellektueller zum Kommunismus im Spiegel dreier Prozesse, in: Ders., Linke Geisterfahrer. Denkanstöße für eine antitotalitäre Linke, Frankfurt a. M. 2001, S. 31-58.

Krausnick, Helmut/Wilhelm, Hans-Heinrich, Die Truppe des Weltanschauungskrieges. Die Einsatzgruppen der Sicherheitspolizei und des SD 1938-1942, Stuttgart 1981.

Kravchenko, Victor A., Ich wählte die Freiheit. Das Private und politische Leben eines Sowjetbeamten. Aus dem Amerikanischen von Albert Heß, Hamburg o. J. (amerik. Ausg.: I chose freedom, New York 1946).

Krivitsky, W[alter] G. (d. i. Samuel Ginsberg), Ich war in Stalins Dienst!, Amsterdam 1940 (amerik. Ausg.: In Stalin's Secret Service, New York 1939).

Krummacher, f. A., (Hg), Die Kontroverse. Hannah Arendt, Eichmann und die Juden, München 1964.

Kuby, Erich, Denazifizierung der Demokraten, in: Der Ruf 2 (1947), H. 11, S. 3.

Ders., Die Geburt der Schuld, in: Der Ruf 2 (1947), H. 23, S. 1. 
Kühnhardt, Ludger/Leutenecker, Gerd/Rupps, Martin/Waltmann, Frank (Hg.), Die doppelte deutsche Diktaturerfahrung. Drittes Reich und DDR - ein historischpolitikwissenschaftlicher Vergleich, Frankfurt a. M. 1994.

Kuhn, Hermann, Bruch mit dem Kommunismus. Über autobiographische Schriften von Ex-Kommunisten im geteilten Deutschland, Münster 1990.

Kunkat, Cornelie, Sidney Hook. Intellektueller zwischen Marxismus und Pragmatismus, Frankfurt a. M./New York 2000.

Kyong-Kun, Kim, Die Neue Zeitung im Dienste der Reeducation für die Deutsche Bevölkerung 1945-1946, Phil. Diss. München 1974.

Lahrem, Stephan, »Freunde, die Freiheit hat die Offensive ergriffen!«. Die Berlin-Tagebücher von Arthur und Mamaine Koestler über den Kongress für kulturelle Freiheit, in: Zeitschrift des Forschungsverbundes SED-Staat, Nr. 17 (2005), S. 57-78.

Lange, Bernd-Peter, George Orwell: »1984«, München 1982.

Lange-Enzmann, Birgit, Franz Borkenau als politischer Denker, Berlin 1996.

Langer, William L., In and Out of the Ivory Tower. The Autobiography of William L. Langer, New York 1977.

Laqueur, Walter, Mein 20. Jahrhundert. Stationen eines persönlichen Lebens, Berlin 2009.

Lasky, Melvin J., Und alles war still. Deutsches Tagebuch 1945, Berlin 2014.

Laurien, Ingrid, Politisch-kulturelle Zeitschriften in den Westzonen 1945-1949. Ein Beitrag zur politischen Kultur der Nachkriegszeit, Frankfurt a. M. 1991.

Leendertz, Ariane, Zeitbögen, Neoliberalismus und das Ende des Westens, oder: Wie kann man die Geschichte des 20. Jahrhunderts schreiben?, in: Vierteljahreshefte für Zeitgeschichte 65 (2017), H. 2, S. 191-217.

Leibholz, Gerhard, Die Auflösung der liberalen Demokratie, in: Deutschland und das autoritäre Staatsbild, München/Leipzig 1933.

Lenin, Wladimir Iljitsch, Ausgewählte Werke in drei Bdn., Berlin 1970.

Lenk, Kurt, Deutscher Konservatismus, Frankfurt a. M./New York 1989.

Leonhard, Jörn, Liberalismus. Zur historischen Semantik eines europäischen Deutungsmusters, München 2001.

Leonhard, Wolfgang, Die Revolution entläßt ihre Kinder, Köln 1955.

Ders., Kreml ohne Stalin, Köln 1959.

Ders., Der Schock des Hitler-Stalin-Paktes. Erinnerungen aus der Sowjetunion, Westeuropa und USA, Freiburg i. Br. 1986.

Lepsius, M. Rainer, Das Erbe des Nationalsozialismus und die politische Kultur der Nachfolgestaaten des »Großdeutschen Reiches«, in: Ders., Demokratie in Deutschland. Soziologisch-historische Konstellationsanalysen. Ausgewählte Aufsätze, Göttingen 1993, S. 229-248.

Lerg, Charlotte A., Melvin J. Lasky als transatlantischer Publizist, in: dies./Maren M. Roth (Hg.), Cold War Politics. Melvin J. Lasky. New York/Berlin/London 2010, S. 31-35.

Lerner, Max, The Pattern of Dictatorship, in: Guy Stanton Ford (Hg.), Dictatorship in the Modern World, Minneapolis (MN) 1935, S. 3-25 (dt. Wiederabdr.: Bruno Seidel/Siegfried Jenkner [Hg.], Wege der Totalitarismusforschung, Darmstadt 1968, S. $30-48$ ).

Lewytzkyj, Borys, Vom Roten Terror zur Sozialistischen Gesetzlichkeit. Der Sowjetische Sicherheitsdienst, München 1961. 
Lietzmann, Hans J., Von der konstitutionellen zur totalitären Diktatur. Carl Joachim Friedrichs Totalitarismustheorie, in: Alfons Söllner/Ralf Walkenhaus/Karin Wieland (Hg.), Totalitarismus - Eine Ideengeschichte des 20. Jahrhunderts, Berlin 1997, S. 174-192.

Ders., Politikwissenschaft im »Zeitalter der Diktaturen« - Die Entwicklung der Totalitarismustheorie Carl Joachim Friedrichs. Mit einem Vorwort von Klaus von Beyme, Opladen 1999.

Lipper, Elinor, Elf Jahre in sowjetischen Gefängnissen und Lagern, Zürich 1950.

Löw, Konrad (Hg.), Totalitarismus, Berlin 1988.

Löwenthal, Richard (d. i. Paul Sering), Der Faschismus, in: Zeitschrift für Sozialismus 1935, H. 26/27, S. $767-787$ u. 839-856.

Ders. (Pseud.), Jenseits des Kapitalismus. Ein Beitrag zur sozialistischen Neuordnung, Lauf bei Nürnberg 1946.

Ders., Chruschtschow und der Weltkommunismus, Stuttgart 1963.

Ders., Nachtrag 1966 zu ders.: Totalitäre und demokratische Revolution, in: Bruno Seidel/Siegfried Jenkner, Wege der Totalitarismus-Forschung, Darmstadt 1968, S. 379-381.

Ders., The Model of the Totalitarian State, in: The Impact of the Russian Revolution 1917-1967. The Influence of Bolshevism on the World Outside Russia. Introduced by Arnold J. Toynbee, London/New York/Toronto 1967, S. 274-351.

Ders., 1917 and After. On the Model of Totalitarian State, in: Encounter 29 (1967), H. 4, S. $21-31$.

Ders., »1917«: An Afterthought on Totalitarian Models, in: Encounter 29 (1967), H. 5, S. $60-64$.

Ders., Von der gelenkten Revolution von oben zur spontanen Evolution von unten, in: Ders./Boris Meissner (Hg.), Sowjetische Innenpolitik. Triebkräfte und Tendenzen, Stuttgart 1968, S. 114-129.

Ders., Der romantische Rückfall. Wege und Irrwege einer rückwärts gewendeten Revolution, 2. Aufl., Stuttgart u. a. 1971.

Ders., Prolog: Dauer und Verwandlung, in: Ders./Hans-Peter Schwarz (Hg.), Die Zweite Republik. 25 Jahre Bundesrepublik Deutschland - eine Bilanz, 2. Aufl., Stuttgart-Degerloch 1974, S. 9-24.

Ders., Vom kalten Krieg zur Ostpolitik, in: Ders./Hans-Peter Schwarz (Hg.), Die Zweite Republik. 25 Jahre Bundesrepublik Deutschland - eine Bilanz, 2. Aufl., StuttgartDegerloch 1974,S. 604-699.

Ders., Gesellschaftswandel und Kulturkrise. Zukunftsprobleme der westlichen Demokratien, Frankfurt a. M. 1979.

Ders., Die Widerstandsgruppe »Neu-Beginnen«. Beiträge zum Thema Widerstand 1933-1945. Bd. 20, Berlin 1982.

Ders./Brandt, Willy, Ernst Reuter. Eine politische Biographie, München 1957.

[Ders. (Pseud)/Frank, Karl/Buttinger, Joseph/Podlipnig, Josef:] Der kommende Weltkrieg. Aufgaben und Ziele des deutschen Sozialismus. Eine Diskussionsgrundlage, Paris 1939.

Loth, Wilfried, Die Teilung der Welt. Geschichte des Kalten Krieges 1941-1955, 6. Aufl., München 1987.

Ludz, Peter Christian, Offene Fragen in der Totalitarismus-Forschung, in: Politische Vierteljahresschrift 2 (1961), H. 4, S. 319-348. 
Ders., Entwurf einer soziologischen Theorie totalitär verfaßter Gesellschaft, in: Bruno Seidel/Siegfried Jenkner, Wege der Totalitarismus-Forschung, Darmstadt 1968, S. 532-559.

Ders., Parteielite im Wandel. Funktionsaufbau, Sozialstruktur und Ideologie der SED-Führung, Köln 1968.

Lüthy, Herbert, Fünf Minuten vor zwölf. Feldzüge und Konferenzen von Stalingrad bis Teheran, St. Gallen 1944.

Ders., Bis zur Neige. Epilog des Zweiten Weltkrieges 1944/45, St. Gallen 1945.

Ders., Frankreichs Uhren gehen anders, Zürich/Stuttgart/Wien 1954.

Ders., La banque protestante en France de la révocation de l' Edit de Nantes à la Révolution. 2 Bde.: Dispersion et regroupement (1685-1730), Bd. 1, Paris 1959; De la banque aux finances (1730-1794). Bd. 2, Paris 1961.

Ders., Adolf Hitler $\uparrow$, in: Ders., Nach dem Untergang des Abendlandes. Zeitkritische Essays, Köln 1964, S. 17-24 (zu erst: Hitler und sein Reich, in: St. Galler Tagblatt vom 2. Mai 1945).

Ders., Die Verheerungen des Krieges«, in: Ders., Nach dem Untergang des Abendlandes. Zeitkritische Essays, Köln 1964, S. 50-79 (Fragment aus: Bis zur Neige. Epilog des Zweiten Weltkrieges 1944/45, St. Gallen 1945).

Ders., Der Friede, der keiner war, in: Ders., Nach dem Untergang des Abendlandes. Zeitkritische Essays, Köln 1964, S. 80-101 (Originaltitel: San Francisco; Fragment aus: Ders., Bis zur Neige. Epilog des Zweiten Weltkrieges 1944/45, St. Gallen 1945).

Ders., Fragmente zu einem Instrumentarium des geistigen Terrors, in: Ders., Nach dem Untergang des Abendlandes. Zeitkritische Essays, Köln 1964, S. 25-49 (Erstveröffentlichung, in: Schweizer Annalen, H. 7 [1945]).

Ders., Die Schweiz als Antithese, Zürich 1969.

Ders., Tugend und Menschenrechte. Zur Topologie politischer Begriffssysteme, Zürich 1989.

Ders., Wo liegt Europa? Zehn Versuche zu den Umtrieben des Zeitgeistes, Zürich 1991.

Ders., Werkausgabe. Edition von Irene Riesen und Urs Bitterli. 7 Bde., Zürich 20022005.

Luks, Leonid, Geschichte Russlands und der Sowjetunion. Von Lenin bis Jelzin, Regensburg 2000.

Maas, Lieselotte, Die Zeitungen des deutschen Exils in Europa von 1933 bis 1939 in Einzeldarstellungen, in: Eberhard Lämmert (Hg.), Handbuch der deutschen Exilpresse 1933-1945, Bd. 4, München/Wien 1990.

Macdonald, Dwight, The Responsibility of Peoples, in: Politics (New York) 2 (1945), S. $82-93$.

Ders., Memoirs of a Revolutionist. Essays in Political Criticism, New York 1957.

Madariagas, Salvador de, Victors, beware, London 1946.

Maier, Hans (Hg.), ’Totalitarismus` und 'politische Religionen<. Konzepte des Diktaturvergleichs. 3 Bde., Paderborn u.a. 1996-2003.

Mampel, Siegfried, Totalitäres Herrschaftssystem: Normativer Charakter - Definitionen - Konstante und variable Essenzialien - Instrumentarium, Berlin 2001.

Marcuse, Herbert, Der Kampf gegen den Liberalismus in der totalitären Staatsauffassung, in: Zeitschrift für Sozialforschung 3 (1934), H. 2, S. 161-195. 
Ders., Reason and Revolution. Hegel and the Rise of Social Theory, New York 1941 (dt. Ausg.: Vernunft und Revolution. Hegel und die Entstehung der Gesellschaftstheorie, Neuwied/Berlin 1962).

Ders., Soviet Marxism. A Critical Analysis, New York 1958 (dt. Ausg.: Die Gesellschaftslehre des sowjetischen Marxismus, Neuwied/Berlin 1964).

Ders., Das Ende der Utopie. Vorträge und Diskussionen in Berlin 1967, Frankfurt a. M. 1980.

Marquardt-Bigman, Petra, Amerikanische Geheimdienstanalysen über Deutschland 1942-1949, München 1995.

Marshall, George C., Vorschläge Marshalls zur amerikanischen Hilfeleistung für die europäischen Länder. Text der Rede vom 5. Juni 1947 an der Harvard-Universität, in: Europa-Archiv 2 (1947), S. 821.

Martin, Marko, Ein Fenster zur Welt. Die Zeitschrift »Der Monat«. Beiträge aus vier Jahrzehnten, Weinheim 2000.

Ders., »Eine Zeitschrift gegen das Vergessen«. Bundesrepublikanische Traditionen und Umbrüche im Spiegel der Kulturzeitschrift Der Monat, Frankfurt a. M. 2003.

Ders., Orwell, Koestler und all die anderen. Melvin J. Lasky und „Der Monat«, Asendorf 1999.

Matz, Elisabeth, Die Zeitungen der US-Armee für die deutsche Bevölkerung (19441946), Münster 1969.

Mau, Hermann, Die »Zweite Revolution« - Der 30. Juni 1934, in: Vierteljahresheft für Zeitgeschichte I (1953), S. 119-137.

Maurach, Reinhard, Das sowjetische Amnestiegesetz, Stuttgart 1953.

Mecklenburg, Jens/Wippermann, Wolfgang (Hg.), »Roter Holocaust«? Kritik des Schwarzbuchs des Kommunismus, Hamburg 1998.

Mehnert, Klaus, Der Sowjetmensch. Versuch eines Porträts nach dreizehn Reisen in die Sowjetunion 1929-1959, Stuttgart u. a. 1959.

Meinecke, Friedrich, Die deutsche Katastrophe, Wiesbaden 1946.

Meinicke, Wolfgang, Zur Entnazifizierung in der sowjetischen Besatzungszone unter Berücksichtigung von Aspekten politischer und sozialer Veränderung 1945-1948, Diss. Berlin (Ost) 1983.

Melgunow, S. P., Der rote Terror in Rußland 1918-1923, Berlin 1924.

Mendelssohn, Peter de, Die Nürnberger Dokumente. Studien zur deutschen Kriegspolitik 1937-1945, Hamburg 1947.

Ders., Der Geist in der Despotie. Versuche über die moralischen Möglichkeiten des Intellektuellen in der totalitären Gesellschaft, Mit einem Vorwort von Karl Jaspers, Berlin-Grunewald 1953.

Ders., Zeitungsstadt Berlin, Menschen und Mächte in der Geschichte der deutschen Presse, Berlin 1959.

Ders., Inselschicksal England. Schrittsteine der Geschichte, München 1965.

Ders., Der Zauberer. Das Leben des deutschen Schriftstellers Thomas Mann, München 1975.

Menden, Alexander, Sinistre Auslassungen. Wie britische Geheimdienste George Orwell bespitzelten, in: Süddeutsche Zeitung vom 5. September 2007.

Merseburger, Peter, Aufbruch ins Ungewisse. Erinnerungen eines politischen Zeitgenossen, München 2021.

Meyers, Jeffrey, Orwell. Wintry Conscience of a Generation, New York 2000. 
Middendorf, Stefanie, »Verstoßenes Wissen«. Emigranten als Deutschlandexperten im »Office of Strategic Services « und im amerikanischen Außenministerium 1943-1955, in: Neue Politische Literatur 46 (2001), S. 23-52.

Möll, Marc-Pierre, Gesellschaft und totalitäre Ordnung. Eine theoriegeschichtliche Auseinandersetzung, Baden-Baden 1998.

Möller, Horst (Hg.), Der rote Holocaust und die Deutschen - Die Debatte um das »Schwarzbuch des Kommunismus«, München 1999.

Mommsen, Hans, Beamtentum im Dritten Reich. Mit ausgewählten Quellen zur nationalsozialistischen Beamtenpolitik, Stuttgart 1966.

Ders., Die Kontinuität der Institution des Berufsbeamtentums und die Rekonstruktion der Demokratie in Westdeutschland, in: Friedrich Gerhard Schwegmann (Hg.), Die Wiederherstellung des Berufsbeamtentums nach 1945. Geburtsfehler oder Stützpfeiler der Demokratisierung in Westdeutschland? Düsseldorf 1986, S. $65-79$.

Monnerot, Jules, Soziologie des Kommunismus, Köln/Berlin 1952 (franz. Ausg.: Sociologie du Communisme, Paris 1949).

Montaigne, Michel de, Essais. Auswahl und Übersetzung von Herbert Lüthy, Zürich 1953.

Mosberg, Helmuth, Reeducation. Umerziehung und Lizenzpresse im Nachkriegsdeutschland, München 1991.

Mühlen, Patrik zur, Säuberungen unter deutschen Spanienkämpfern, in: Exilforschung. Ein internationales Jahrbuch 1 (1983), S. 165-176.

Müller, Carl Wolfgang, Der Monat. Eine internationale Zeitschrift für Politik und geistiges Leben (unveröffentl. Manuskript), Freie Universität Berlin 1951.

Müller, Jan-Werner, Demokratie für Verlierer, in: Merkur 75 (2021), H. 863, S. 5-17.

Müller, Reinhard, Willi Münzenberg, in: Manfred Asendorf/Rolf von Bockel (Hg.), Demokratische Wege. Deutsche Lebensläufe aus fünf Jahrhunderten, Stuttgart/Weimar 1997, S. 439-441.

Ders., Menschenfalle Moskau. Exil und stalinistische Verfolgung, Hamburg 2001.

Ders., Herbert Wehner - Moskau 1937, Hamburg 2004.

Ders., Aus der Moskauer Kaderakte Arthur Koestlers - Zur Vorgeschichte der "Sonnenfinsternis«, in: Exil. Forschung, Erkenntnisse, Ergebnisse 24 (2004), H. 2, S. $44-60$.

Münkler, Herfried, Populismus, Demokratismus, Cäsarismus. Die Herausforderung der liberalen Demokratie, Merkur 75 (2021), H. 863, S. 26-41.

Naumann, Klaus, Hannah Arendt und die Ex-Kommunisten, in: Mittelweg 36, 2 (1993), H. 2, S. 30-40.

Negt, Oskar, Achtundsechzig. Politische Intellektuelle und die Macht, Göttingen 1995.

Neumann, Franz [L.]/Ders., Angst und Politik [1954], in: Ders., Demokratischer und autoritärer Staat. Beiträge zur Soziologie der Politik, Frankfurt a. M. 1967, S. 184214.

Ders., Ökonomie und Politik im zwanzigsten Jahrhundert [1955], in: Ders., Demokratischer und autoritärer Staat. Beiträge zur Soziologie der Politik, Frankfurt a. M. 1967, S. 171-183.

Ders., Intellektuelle und politische Freiheit [1955], in: Ders., Demokratischer und autoritärer Staat. Beiträge zur Soziologie der Politik, Frankfurt a. M. 1967, S. 215-229. 
Ders., Ökonomie und Politik im zwanzigsten Jahrhundert [1955], in: Demokratischer und autoritärer Staat. Beiträge zur Soziologie der Politik, Frankfurt a. M. 1967, S. $171-183$.

Ders., Notizen zur Theorie der Diktatur [1957], in: Ders., Demokratischer und autoritärer Staat. Beiträge zur Soziologie der Politik, Frankfurt a. M. 1967, S. 147-170.

Ders.: Der Niedergang der deutschen Demokratie [1933], in: Ders., Wirtschaft, Staat, Demokratie. Aufsätze 1930-1954. Hg. von Alfons Söllner, Frankfurt a. M. 1978, S. $103-123$.

Ders., Die Umerziehung der Deutschen und das Dilemma des Wiederaufbaus [1947], in: Ders., Wirtschaft, Staat, Demokratie. Aufsätze 1930-1954. Hg. von Alfons Söllner, Frankfurt a. M. 1978, S. 290-308.

Ders., Militärregierung und Wiederbelebung der Demokratie in Deutschland [1948], in: Ders., Wirtschaft, Staat, Demokratie. Aufsätze 1930-1954. Hg. von Alfons Söllner, Frankfurt a. M. 1978, S. 309-326;

Ders., Deutsche Demokratie [1950], in: Ders., Wirtschaft, Staat, Demokratie Aufsätze 1930-1954. Hg. von Alfons Söllner, Frankfurt a. M. 1978, S. 327-372.

Ders., Die Wissenschaft der Politik in der Demokratie [1950], in: Ders., Wirtschaft, Staat, Demokratie Aufsätze 1930-1954. Hg. von Alfons Söllner, Frankfurt a. M. 1978, S. 373-392.

Ders., Intellektuelle Emigration und Sozialwissenschaft [1952], in: Ders., Wirtschaft, Staat, Demokratie. Aufsätze 1930-1954. Hg. von Alfons Söllner, Frankfurt a. M. 1978, S. 402-423.

Ders., Behemoth. Struktur und Praxis des Nationalsozialismus 1933-1944. Hg. und mit einem Nachwort von Gert Schäfer, Frankfurt a. M. 1984 (amerik. Ausg.: New York 1942 bzw. 1944).

Neumann, Heinz, Was ist Bolschewisierung?, Hamburg 1925.

Neumann, Sigmund, Permanent Revolution. The Total State in a World at War, New York/London 1942.

Neusüss-Henkel, Ermenhild, Die SS, Hannover/Frankfurt a. M. 1956.

Nitti, Francesco, Bolschewismus, Fascismus und Demokratie, München 1926.

Nolte, Ernst, Der Faschismus in seiner Epoche, München 1963.

Ders., Theorien über den Faschismus, Köln 1967.

Ders., Deutschland und der Kalte Krieg, Stuttgart 1985.

Ders., Vergangenheit, die nicht vergehen will. Eine Rede, die geschrieben, aber nicht gehalten werden konnte, in: Frankfurter Allgemeine Zeitung vom 6. Juni 1986.

Ders., Der europäische Bürgerkrieg 1917-1945. Nationalsozialismus und Bolschewismus, Frankfurt a. M./Berlin (West) 1987.

Ders., Vergangenheit, die nicht vergehen will. Eine Rede, die geschrieben, aber nicht gehalten werden konnte, in: »Historikerstreit«. Die Dokumentation der Kontroverse um die Einzigartigkeit der nationalsozialistischen Judenvernichtung, 9. Aufl., München 1995, S. 39-47.

Nolzen, Armin, Franz Leopold Neumanns »Behemoth«. Ein vergessener Klassiker der NS-Forschung, in: Zeithistorische Forschungen/Studies in Contemporary History 1 (2004), S. 150-153.

Nordmann, Ingeborg, Hannah Arendt, Frankfurt a. M./New York 1994.

Ogorreck, Ralf/Rieß, Volker, Fall 9: Der Einsatzgruppenprozeß (gegen Otto Ohlendorf und andere), in: Gerd R. Ueberschär (Hg.), Der Nationalsozialismus vor Gericht. 
Die alliierten Prozesse gegen Kriegsverbrecher und Soldaten 1943-1952, Frankfurt a. M. 1999, S. 164-175.

Orlow, Alexander, Kremlgeheimnisse, Würzburg 1953 (amerik. Ausg.: The Secret History of Stalin's Crimes, New York 1953).

Orwell, George, Down and Out in London and Paris, London 1933 (dt. Ausg.: Erledigt in Paris und London, Zürich 1978).

Ders., Burmese Day, New York 1934 (dt. Übers.: Tage in Burma, Zürich 1982).

Ders., A Clergyman's Daughter, London 1935 (dt. Übers.: Eine Pfarrerstochter, Zürich 1983).

Ders., Keep the Aspidistra Flying, London 1936 (dt. Ausg.: Die Wonnen der Aspidistra, Zürich 1983).

Ders., Homage to Catalonia, London 1938 (dt. Ausg.: Mein Katalonien, München 1964).

Ders., Animal Farm, London 1945 (dt. Ausg.: Farm der Tiere, Zürich 1946).

Ders., Nineteen Eighty-Four, London 1949 (dt. Ausg.: 1984, Zürich 1950).

Ders., Warum ich schreibe, in: Im Innern des Wals. Erzählungen und Essays. Aus dem Engl. von Felix Gasbarra, Zürich 1975, S. 7-17 (engl. Ausg.: Inside the Whale, London 1940).

Ders., Rezension von: Mein Kampf von Adolf Hitler, in: Das George Orwell Lesebuch. Essays, Reportagen, Betrachtungen. Hg. und mit einem Nachwort von Fritz Senn. Aus dem Engl. von Tina Richter, Zürich 1981, S. 240-243 (engl. Orig. in: New English Weekly vom 21. März 1940).

Ders., Die Diskriminierung Farbiger, in: Das George Orwell Lesebuch. Essays, Reportagen, Betrachtungen. Hg. und mit einem Nachwort von Fritz Senn. Aus dem Engl. von Tina Richter, Zürich 1981, S. 217-219 (engl. Orig.: As I Please, in: Tribune vom 11. August 1944.

Ders., Antisemitismus in Großbritannien, in: Das George Orwell Lesebuch. Essays, Reportagen, Betrachtungen. Hg. und mit einem Nachwort von Fritz Senn. Aus dem Engl. von Tina Richter, Zürich 1981, S. 220-232 (engl. Orig. in: Contemporary Jewish Record im April 1945).

Ders., Betrachtungen zur Judenfrage, in: Das George Orwell Lesebuch. Essays, Reportagen, Betrachtungen. Hg. und mit einem Nachwort von Fritz Senn. Aus dem Engl. von Tina Richter, Zürich 1981, S. 233-235 (engl. Orig. in: Observer vom 7. November 1948).

Paloczi-Horvath, George, Rebellion der Tatsachen. Die Zukunft Rußlands und des Westens, Frankfurt a. M. 1963.

Ders., Stalin, Zürich 1968.

Perels, Joachim, Franz L. Neumanns Beitrag zur Konzipierung der Nürnberger Prozesse, in: Matthias Iser/David Strecker (Hg.), Kritische Theorie der Politik. Franz Neumann - eine Bilanz, Baden-Baden 2002, S. 83-94.

Petersen, Jens, Die Geschichte des Totalitarismusbegriffs in Italien, in: Hans Maier (Hg.), 'Totalitarismus und >politische Religionen $<$. Konzepte des Diktaturvergleichs, Paderborn u.a. 1996, S. 15-35.

Pingel-Schliemann, Sandra, Zersetzen. Strategie einer Diktatur, Berlin 2002.

Popper, Karl, The Open Society and Its Enemies, 2 Bde., London 1945.

Pross, Harry, Literatur und Politik. Geschichte und Programme der politisch-literarischen Zeitschriften im deutschen Sprachgebiet seit 1870, Freiburg i. Br. 1963. 
Pross, Helge, Einleitung, in: Franz Neumann, Demokratischer und autoritärer Staat. Studien zur politischen Theorie. Hg. und mit einem Vorwort von Herbert Marcuse. Eingeleitet von Helge Pross, Frankfurt a. M. 1986, S. 9-27.

Radlmaier, Steffen (Hg.), Der Nürnberger Lernprozess. Von Kriegsverbrechern und Starrreportern, Frankfurt a. M. 2001.

Rauch, Georg von, Geschichte des bolschewistischen Rußland, Frankfurt a. M./Hamburg 1963 (dt. Erstausg.: Wiesbaden 1955).

Rauschning, Hermann, Die Revolution des Nihilismus, Zürich 1938.

Ders., Gespräche mit Hitler, Zürich 1940.

[Red. Der Ruf], Irrealistische Säuberung. Zur Reform des Befreiungsgesetzes, in: Der Ruf 2 (1947), H.19, S. 5 f.

Reich, Richard/Bondy, Béatrice (Hg.), Homme de Lettres. Freundesgabe für François Bondy, Zürich 1985.

Reichel, Peter, Der tragische Kanzler. Hermann Müller und die SPD in der Weimarer Republik, München 2018.

Ders., Bitte keine neue Totalitarismus-Debatte! Gegen die schrecklichen Vereinfacher, die uns die Rot-gleich-Braun-Linie der antikommunistischen fünfziger Jahre wieder aufzwingen wollen, in: Die Tageszeitung vom 4. März 1992, S. 11.

Ders., Zwischen Dämonisierung und Verharmlosung: Das NS-Bild und seine politische Funktion in den 5oer-Jahren. Eine Skizze, in: Axel Schildt/Arnold Sywottek (Hg.), Modernisierung im Wiederaufbau: die westdeutsche Gesellschaft der 5oerJahre, Bonn 1993, S. 679-692.

Ders., Vergangenheitsbewältigung in Deutschland. Die Auseinandersetzung mit der NS-Diktatur von 1945 bis heute, München 2001.

Reinhold, Ursula/Schlenstedt, Dieter/Tannenberger, Horst (Hg.), Erster Deutscher Schriftstellerkongreß, 4. bis 8. Oktober 1947. Protokoll und Dokumente, Berlin 1997.

Reitlinger, Gerald, Die Endlösung. Hitlers Versuch der Ausrottung der Juden 19391945, Berlin 1956 (engl. Orig.: The Final Solution - The Attempt to Exterminate the Jews of Europe 1939-1945, London 1953).

Richert, Ernst, Die neue Gesellschaft in Ost und West, Analyse einer lautlosen Revolution, Gütersloh 1966.

Ritte, Jürgen, Ein Sündenfall. Ulrike Ackermanns Studie über die Intellektuellen, in: Neue Zürcher Zeitung vom 7. März 2001, S. 35.

Ritter, Gerhard, Europa und die deutsche Frage. Betrachtungen über die geschichtliche Eigenart des deutschen Staatsdenkens, München 1948.

Rohrwasser, Michael, Der Stalinismus und die Renegaten. Die Literatur der Exkommunisten, Stuttgart 1991.

Ders./Krebs, Richard: Der Kominternagent, in: Ders., Der Stalinismus und die Renegaten. Die Literatur der Exkommunisten, Stuttgart 1991, S. 177-231.

Ders., Über Jan Valtins Buch »Tagebuch der Hölle«], unveröff. Vortragsmanuskript: Oktober 1993.

Ders., Was haben sie verraten, die Renegaten? Zwölf Thesen zur Faszination des Stalinismus, in: Werner von Bergen/Walter H. Pehle (Hg.), Denken im Zwiespalt. Über den Verrat von Intellektuellen im 20. Jahrhundert, Frankfurt a. M. 1996, S. 61-81. 
Ders., Totalitarismustheorie und Renegatenliteratur, in: Alfons Söllner/Ralf Walkenhaus/Karin Wieland (Hg.), Totalitarismus. Eine Ideengeschichte des 20. Jahrhunderts, Berlin 1997, S. 105-116.

Roloff, Ernst-August, Exkommunisten. Abtrünnige des Weltkommunismus. Ihr Leben und ihr Bruch mit der Partei in Selbstdarstellungen, Mainz 1969.

Rosenberg, Alfred, Totaler Staat?, in: Völkischer Beobachter vom 9. Januar 1934.

Roth, Maren, In einem Vorleben war ich Europäer - Melvin J. Lasky als transatlantischer Mittler im kulturellen Kalten Krieg, in: Jahrbuch für Historische Kommunismusforschung 10 (2014), S. 139-156.

Rothfels, Hans, Die deutsche Opposition gegen Hitler. Eine Würdigung, 2. Aufl., Krefeld 1951.

Ders., Zeitgeschichte als Aufgabe, in:Vierteljahreshefte für Zeitgeschichte 1 (1953), H. 1, S. $1-8$.

Rougemont, Denis de, Journal aus Deutschland 1935-1936. Mit einem Nachwort von Jürg Altwegg. Aus dem Franz. von Tobias Scheffel, Wien 1998.

Rousset, David, L'univers concentrationnaire, Paris 1946.

Ders., Les Jours de Notre Mort, Paris 1947.

Rudzka, Marta, Workuta. Weg zur Knechtschaft, Zürich 1948.

Rühle, Otto, Brauner und roter Faschismus, in: Ders., Schriften, Reinbek bei Hamburg 1971, S. 7-71.

Rupieper, Hermann-J., Amerikanische Besatzungspolitik, in: Wolfgang Benz (Hg.), Deutschland unter alliierter Besatzung: 1945-1949/55, Berlin 1999, S. 33-47.

Sahl, Hans, Das Exil im Exil. Memoiren eines Moralisten II, Frankfurt a. M. 1990.

Salter, Ernest J., Deutschland und der Sowjetkommunismus. Die Bewährung der Freiheit, München 1961.

Saunders, Francis Stonor, Wer die Zeche zahlt ... Der CIA und die Kultur im Kalten Krieg. Aus dem Engl. von Markus P. Schupfner, Berlin 2001.

Schäfer, Gert, Franz Neumanns Behemoth und die heutige Faschismusdiskussion, in: Franz Neumann, Behemoth. Struktur und Praxis des Nationalsozialismus 19331944, Frankfurt a. M. 1984, S. 663-776.

Schäfer, Michael, Luigi Sturzo als Totalitarismustheoretiker, in: Hans Maier (Hg.), >Totalitarismus und >politische Religionen $<$. Konzepte des Diktaturvergleichs, Paderborn u.a. 1996, S. 59-70.

Schäfer, Wolfgang, NSDAP. Entwicklung und Struktur der Staatspartei des Dritten Reiches, Hannover/Frankfurt a. M. 1956.

Schildt, Axel, Medien-Intellektuelle in der Bundesrepublik. Herausgegeben und mit einem Nachwort versehen von Gabriele Kandzora und Detlef Siegfried, Göttingen 2020.

Ders., Westlich, demokratisch. Deutschland und die westlichen Demokratien im 20. Jahrhundert, in: Anselm Doering-Manteuffel (Hg.), Strukturmerkmale der deutschen Geschichte des 20. Jahrhunderts, München 2006, S. 225-239.

Ders., Zwischen Abendland und Amerika. Studien zur westdeutschen Ideenlandschaft der 50er-Jahre, München 1999.

Ders., Kultur und geistiges Leben, in: Wolfgang Benz (Hg.), Deutschland unter alliierter Besatzung: 1945-1949/55, Berlin 1999, S. 134-140.

Ders./Siegfried, Detlef, Deutsche Kulturgeschichte. Die Bundesrepublik - 1945 bis zur Gegenwart, Bonn 2009. 
Schivelbusch, Wolfgang, Vor dem Vorhang. Das geistige Berlin 1945-1948, Frankfurt a. M. 1997.

Schlangen, Walter, Die Totalitarismus-Theorie. Entwicklung und Probleme, Stuttgart u. a. 1976.

Schlesinger, Arthur M. jr., The Vital Center. The Politics of Freedom, Boston 1949.

Schmidt, Oliver, Jenseits der Ideologien. Vor zehn Jahren starb der Politologe Richard Löwenthal, in: Tagesspiegel vom 9. August 2001.

Schmidt-Eenboom, Erich, Geheimdienst, Politik und Medien. Meinungsmache UNDERCOVER, Berlin 2004.

Schmitt, Carl, Der Hüter der Verfassung, Tübingen 1931.

Ders., Die Wendung zum totalen Staat, in: Europäische Revue 7 (1931), S. 241-250 (wiederabgedr. in: Ders., Positionen und Begriffe im Kampf mit Weimar-GenfVersailles 1923-1939, Hamburg 1940, S. 146-158).

Schoeller Wilfried f. (Hg.), Diese merkwürdige Zeit. Leben nach der Stunde Null. Ein Textbuch aus der Neuen Zeitung, Frankfurt a. M. 2005.

Schorn, Hubert, Der Richter im Dritten Reich. Geschichte und Dokumente, Frankfurt a. M. 1959.

Schröder, Hans-Christoph, George Orwell. Eine intellektuelle Biographie, München 1988.

Schulz, Gerhard, Der Begriff des Totalitarismus und der Nationalsozialismus, in: Soziale Welt 12 (1961), H. 2, S. 112-128.

Schwab-Felisch, Hans, Einleitung, in: Ders. (Hg.), Der Ruf. Eine deutsche Nachkriegszeitschrift. Mit einem Geleitwort von Hans Werner Richter, München 1962, S. 1018.

Ders., Der Monat - Ein Zeitdokument, in: Merkur 25 (1971), S. 405-409.

Schwartz, Thomas Alan, Die Atlantik-Brücke. John McCloy und das Nachkriegsdeutschland, Frankfurt a. M./Berlin 1992.

Ders., Die Begnadigung deutscher Kriegsverbrecher. John J. McCloy und die Häftlinge von Landsberg, in: VfZ 38 (1990), S. 375-414.

Schweigler, Gebhard, Institutionen, Entscheidungsprozesse und Instrumente der Außenpolitik, in: Willi Paul Adams u.a. (Hg.), Länderbericht USA, Bd. 2, Außenpolitik/Gesellschaft/Kultur-Religion-Erziehung, 2., akt. und erg. Aufl., Bonn 1992, S. 3-31.

Scott-Smith, Giles, The Politics of Apolitical Culture Freedom, the CIA and Post-War American Hegemony, London/New York 2002.

Ders./Lerg, Charlotte A., Campaigning Culture and the Global Cold War. The Journals of the Congress for Cultural Freedom. London: Palgrave Macmillan 2017.

Sering, Paul (siehe Richard Löwenthal).

Serge, Victor, Erinnerungen eines Revolutionärs 1901-1941, Hamburg 1977 (franz. Orig.: Mémoires d' un Révolutionnaire 1901-1941, Paris 1951).

Seubert, Harald, Erinnerungen an den `Engagierten Beobachter in veränderter Zeit. Über Raymond Aron als Theoretiker des Totalitarismus und der nuklearen Weltlage, in: Hans Maier/Michael Schäfer (Hg.), »Totalitarismus« und »politische Religionen«. Konzepte des Diktaturvergleichs, Bd. 2, Paderborn u.a. 1997, S. 311-361.

Siegel, Achim (Hg.), Totalitarismustheorien nach dem Ende des Kommunismus, Köln/ Weimar 1998. 
Silone, Ignazio, Brief nach Moskau vom 30. August 1936, in: europäische ideen (1975), H. 9, S. 37-39 (zuerst in: Arbeiter-Zeitung [Basel] vom 24. September 1936).

Ders., Der Fascismus. Seine Entstehung und seine Entwicklung, Zürich 1934.

Ders., Die Schule der Diktaturen, Zürich 1938.

Smith, Arthur L., Die Hexe von Buchenwald, Köln 1983.

Smith, Bradleyf., Der Jahrhundertprozeß. Die Motive der Richter von Nürnberg Anatomie einer Urteilsfindung, Frankfurt a. M. 1977.

Ders., The Shadow Warriors. OSS and the Origins of the CIA, New York 1983.

Smith, Richard Harris, OSS. The Secret History of America's First Central Intelligence Agency, Berkley 1972.

Söllner, Alfons, Franz L. Neumann - Skizzen zu einer intellektuellen und politischen Biographie, in: Franz L. Neumann. Wirtschaft, Staat, Demokratie. Aufsätze 19301954. Hg. von dems., Frankfurt a. M. 1978, S. 7-56.

Ders., Geschichte und Herrschaft. Studien zur materialistischen Sozialwissenschaft 1929-1942, Frankfurt a. M. 1979.

Ders., Neumann zur Einführung. Mit einem Beitrag von Theodor W. Adorno, Hannover 1982.

Ders. (Hg.), Zur Archäologie der Demokratie in Deutschland, 2 Bde., Frankfurt a. M. 1986.

Ders./Walkenhaus, Ralf/Wieland, Karin (Hg.), Totalitarismus - Eine Ideengeschichte des 20. Jahrhunderts, Berlin 1997.

Ders., Das Totalitarismuskonzept in der Ideengeschichte des 20. Jahrhunderts, in: Ders./Ralf Walkenhaus/Karin Wieland (Hg.), Totalitarismus - Eine Ideengeschichte des 20. Jahrhunderts, Berlin 1997, S. 10-21.

Ders., Sigmund Neumanns »Permanent Revolution«. Ein vergessener Klassiker der vergleichenden Diktaturforschung, in: Ders./Ralf Walkenhaus/Karin Wieland (Hg.), Totalitarismus. Eine Ideengeschichte des 20. Jahrhunderts, Berlin 1997, S. $53-65$.

Ders., Neumann als Archetypus - die Formierung des political scholar im 20. Jahrhundert, in: Matthias Iser/David Strecker (Hg.), Kritische Theorie der Politik. Franz Neumann - eine Bilanz, Baden-Baden 2002, S. 39-55.

Solschenizyn, Alexander, L'Archipel du Goulag, 1918-1956. Essai d'investigation littéraire, 3 Bde., Paris 1974-76 (dt. Ausg.: Der Archipel Gulag 1918-1956. Versuch einer künstlerischen Bewältigung, Bde. 1-3, Bern/München 1974-1976).

Sontheimer, Kurt, Antidemokratisches Denken in der Weimarer Republik. Die politischen Ideen des deutschen Nationalismus zwischen 1918 und 1933, Stuttgart 1962

Souvarine, Boris, Stalin. Anmerkungen zur Geschichte des Bolschewismus, München 1980 (amerik. Ausg.: Stalin. A Critical Survey of Bolshevism, New York 1939; dt. Ausg.: Stalin. Anmerkungen zur Geschichte des Bolschewismus, Amsterdam 1940). Spender, Stephen Deutschland in Ruinen. Ein Bericht. Aus dem Engl. von Joachim Utz, Frankfurt a. M. 1998.

Sperber, Manés, Zur Analyse der Tyrannis, Paris 1938.

Ders., Bis man mir Scherben auf die Augen legt. All das Vergangene ..., Wien 1977.

Spiel, Hilde, Der Erzähler Peter de Mendelssohn, in: Peter de Mendelssohn, Die Kathedrale. Eine Sommernachtmahr. Mit einem Nachwort von Hilde Spiel, Berlin 1988, S. $237-264$.

Dies., Die hellen und die finsteren Zeiten. Erinnerungen 1911-1946, München 1989. 
Dies., Welche Welt ist meine Welt? Erinnerungen 1946-1989, Frankfurt a. M./Wien 1991.

Stammer, Otto, Aspekte der Totalitarismusforschung, in: Soziale Welt 12 (1961), H. 2, S. $97-128$.

Stark, Joachim, Das unvollendete Abenteuer. Geschichte, Gesellschaft und Politik im Werk Raymond Arons, Würzburg 1986.

Ders. (Hg.), Raymond Aron: Über Deutschland und den Nationalsozialismus. Frühe politische Schriften 1930-1939, Opladen 1993.

Ders., Raymond Aron und der Gestaltwandel des Totalitarismus, in: Alfons Söllner/ Ralf Walkenhaus/Karin Wieland (Hg.), Totalitarismus. Eine Ideengeschichte des 20. Jahrhunderts, Berlin 1997, S. 195-207.

Stein, Hannes, George Orwell zum 100. Geburtstag. Unterwegs auf der und zur schottischen Insel Jura, wo Orwell Motorrad fuhr, Gemöse zog, Torf stach und »Neunzehnhundertvierundachzig« schrieb, in: Die Welt vom 21. Juni 2003.

Steinberg, Isaak, Gewalt und Terror in der Revolution. Oktoberrevolution oder Bolschewismus, Berlin 1931.

Steinberger, Petra, Wo die Kommunisten nisten. Streit um das Gesamtwerk: War Orwell selbst der >große Bruder«? «, in: Süddeutsche Zeitung vom 2. Juli 1998.

Steinmeier, Frank-Walter, Belastungen und Bewährungen von Freiheit und Demokratie, in: Merkur 75 (2021), H. 863, S. 17-25.

Stern, Fritz, Fünf Deutschland und ein Leben. Erinnerungen. Aus dem Engl. von Friedrich Griese, München 2007.

Ders., Kulturpessimismus als Gefahr. Eine Analyse nationaler Ideologie in Deutschland. Mit einem Vorwort von Norbert Frei, Stuttgart 2005 (amerik. Orig.: The Politics of Cultural Despair, University of California Press, Berkeley 1961).

Sternberg, Fritz, Der Faschismus an der Macht, Amsterdam 1935.

Sternberger, Dolf/Storz, Gerhard/Süskind, Wilhelm E., Aus dem Wörterbuch des Unmenschen, Hamburg 1957.

Stöver, Bernd, Die Befreiung vom Kommunismus. Amerikanische Liberation Policy im Kalten Krieg 1947-1991, Köln 2002.

Ders., Der Kalte Krieg 1947-1991. Geschichte eines radikalen Zeitalters, München 2007.

Stoll, Angelika, Die Totalitarismuskonzeption von C. J. Friedrich in Kritik und Gegenkritik, Diss. Bayreuth 1980.

Streber, Martina, Die Hüter der Begriffe. Politische Sprachen der Konservativen in Großbritannien und der Bundesrepublik Deutschland, 1945-1980, Berlin/Boston 2017, S. 157-163.

Strothmann, Dietrich, Nationalsozialistische Literaturpolitik. Ein Beitrag zur Publizistik im Dritten Reich, Bonn 1960.

Sturzo, Luigi, Italien und der Faschismus, Köln 1926.

Symposium on the Totalitarian State. From the Standpoints of History, Political Science, Economics and Sociology, Nov. 17, 1939. Proceedings of the American Philosophical Society (Philadelphia) 82 (1940), H. 1.

Talmon, Jacob L., Die Ursprünge der totalitären Demokratie, Köln und Opladen 1961 (engl. Orig.: The Origins of Totalitarian Democracy, London 1952).

Ders., Politischer Messianismus. Die romantische Phase, Köln und Opladen 1963 (engl. Orig.: Political Messianism. The Romantic Phase, London 1960). 
Ders.,The Myth of the Nation and the Vision of Revolution. The Origins of Totalitarian Polarisation in the Twentieth Century, London 1981.

Tashjean, John E., Franz Borkenau. A Study of his social and political Ideas. Unveröffentl. Diss., Georgetown University Washington 1962.

Taylor, D. J., Orwell: The Life, London 2003.

Taylor, Telford, Die Nürnberger Prozesse. Hintergründe, Analysen und Erkenntnisse aus heutiger Sicht, 3. Aufl., München 1996.

Thomas, Gina, Schweine sind doch auch nur Menschen. Inklusive des ersten Anschwärzbuches des Kommunismus: Jetzt ist das Werk George Orwells endlich komplett, in: Frankfurter Allgemeine Zeitung vom 18. Juli 1998.

Tichy, Frank, Das Ende des Encounter, in: Medien \& Zeit 6 (1991), H.3, S. 41-47.

Tillich, Paul, The Totalitarian State and the Claims of the Church, in: Social Research 1 (1934), 4, S. 405-433.

Traverso, Enzo, Die Verantwortung der Intellektuellen: Dwight Macdonald und JeanPaul Sartre, in: Ders., Auschwitz denken. Die Intellektuellen und die Shoah, Hamburg 2000 , S. $281-329$.

Troy, Thomas f., Wild Bill and Intrepid: Donovan, Stephenson, and the Origin of the CIA, New Haven 1996.

Ueberschär, Gerd R. (Hg.), Der Nationalsozialismus vor Gericht. Die alliierten Prozesse gegen Kriegsverbrecher und Soldaten 1943-1952, Frankfurt a. M. 1999.

Vaillant, Jérôme, Der Ruf. Unabhängige Blätter der jungen Generation (1945-1949). Eine Zeitschrift zwischen Illusion und Anpassung. Mit einem Vorwort von Harold Hurwitz, München/New York/Paris 1978.

Valtin, Jan (d. i. Richard Krebs), Out of the Night, New York 1941 (dt. Ausg.: Tagebuch der Hölle, Köln 1957).

Voegelin, Eric, Die politischen Religionen, hg. und mit einem Nachwort versehen von Peter J. Opitz, München 1993.

Ders., Hitler und die Deutschen. Hg. von Manfred Henningsen, München 2006.

Vollnhals, Clemens (Hg.), Entnazifizierung. Politische Säuberung und Rehabilitierung in den vier Besatzungszonen 1945-1949, München 1991.

Ders., Evangelische Kirche und Entnazifizierung 1945-1949. Die Last der nationalsozialistischen Vergangenheit, München 1989.

Vorländer, Hans, Demokratie. Geschichte, Formen und Theorien, 3., überarbeitete Aufl., München 2019.

Wald, Alan M., The New York Intellectuals. The Rise and Decline of the Anti-Stalinist Left from the 1930s to the 1980s, Chapel Hill/London 1987.

Waldenfels, Ernst von, Der Spion, der aus Deutschland kam. Das geheime Leben des Seemanns Richard Krebs, Berlin 2002.

Waldmüller, Monika, Die Wandlung, Marbach a. N. 1988.

Walter, Hans-Albert, Deutsche Exilliteratur 1933-1950, 4 Bde., Stuttgart 1978.

Warlimont, Walter Im Hauptquartier der deutschen Wehrmacht 1939-1945, Frankfurt a. M. 1962.

Wehler, Hans-Ulrich, Entsorgung der deutschen Vergangenheit? Ein polemischer Essay zum »Historikerstreit«, München 1988.

Wehner, Herbert, Zeugnis. Hg. von Gerhard Jahn, Köln 1982.

Weiner, Tim, CIA. Die ganze Geschichte, 2. Aufl., Frankfurt a. M. 2008 (amerik. Orig. 2007). 
Weißberg-Cybulski, Alexander, Im Verhör. Ein Überlebender der stalinistischen Säuberungen berichtet. Mit einem Vorwort von Arthur Koestler und einem biographischen Nachwort von Ella Lingens, Wien/Zürich 1993 (dt. Ausg.: Hexensabbat. Die Gedankenpolizei - Die große Tschistka, Frankfurt a. M. 1951).

Welsh, Helga, »Antifaschistisch-demokratische Umwälzung« und politische Säuberung in der sowjetischen Besatzungszone Deutschlands, in: Klaus-Dietmar Henke/ Hans Woller (Hg.), Politische Säuberung in Europa. Die Abrechnung mit Faschismus und Kollaboration nach dem Zweiten Weltkrieg, München 1991, S. 84-107.

Wende-Hohenberger, Waltraud (Hg.), Der erste gesamtdeutsche Schriftstellerkongreß nach dem Zweiten Weltkrieg im Ostsektor Berlins vom 4. bis 8. Oktober 1947, Frankfurt a. M./Bern/New York/Paris 1988, Vorwort I-XXIX.

Wengst, Udo, Beamtentum zwischen Reform und Tradition. Beamtengesetzgebung in der Gründungsphase der Bundesrepublik Deutschland 1948-1953, Düsseldorf 1988.

Wette, Wolfram, Das Bild der Wehrmachts-Elite nach 1945, in: Gerd R. Ueberschär (Hg.), Hitlers militärische Elite. Bd. 2: Vom Kriegsbeginn bis zum Weltkriegsende, Darmstadt 1998, S. 293-308.

Wettig, Gerhard, Von der Entmilitarisierung zur Aufrüstung in beiden Teilen Deutschlands 1945-1952, in: Bruno Thoss (Hg. im Auftr. des Militärgeschichtlichen Forschungsamtes unter Mitarb. von Wolfgang Schmidt), Vom Kalten Krieg zur deutschen Einheit: Analysen und Zeitzeugenberichte zur deutschen Militärgeschichte 1945 bis 1995, München 1995, S. 3-36.

Ders., Berlin vor den Herausforderungen des Kalten Krieges 1945-1989, in: Werner Süß/Ralf Rytlewski (Hg.), Berlin. Die Hauptstadt. Vergangenheit und Zukunft einer europäischen Metropole, Bonn 1999, S. 157-186.

Wetzel, Jürgen, Berlin, in: Wolfgang Benz (Hg.), Deutschland unter alliierter Besatzung: 1945-1949/55, Berlin 1999, S. 385-390.

Wetzlaugk, Udo, Berliner Blockade und Luftbrücke 1948/49, Berlin 1998.

Wiggershaus, Rolf, Die Frankfurter Schule. Geschichte - Theoretische Entwicklung Politische Bedeutung, 3. Aufl., München 1991.

Wilford, Hugh, The New York Intellectuals. From Vanguard to Institution, New York 1995.

Winkler, Heinrich August, Der lange Weg nach Westen, 2 Bde., München 2000.

Wippermann, Wolfgang, Totalitarismustheorien: die Entwicklung der Diskussion von den Anfängen bis heute, Darmstadt 1997.

Ders., Der nekrophile Antikommunismus der »aufgeklärten Linken«, in: Jens Mecklenburg/Ders. (Hg.), »Roter Holocaust«? Kritik des Schwarzbuchs des Kommunismus, Hamburg 1998, S. 239-250.

Ders., Dämonisierung durch Vergleich: DDR und Drittes Reich, Berlin 2009.

Wittfogel, Karl August, Oriental Despotism. A Comparative Study of Total Power, New Haven/New York 1957 (dt. Ausg.: Die Orientalische Despotie. Eine vergleichende Untersuchung totaler Macht, Köln 1962).

Wreszin, Michael, A Rebel in Defense of Tradition. The Life and Politics of Dwight Macdonald, New York 1994.

Wrochem, Oliver von, Erich von Manstein, Vernichtungskrieg und Geschichtspolitik, Paderborn 2006.

Ders., Die Auseinandersetzung mit Wehrverbrechen im Prozess gegen den Generalfeldmarschall Erich von Manstein 1949, in: ZfG 46 (1998), S. 329-353. 
Yergin, Daniel, Der zerbrochene Frieden. Der Ursprung des Kalten Krieges und die Teilung Europas, Frankfurt a. M. 1979.

Young-Bruehl, Elisabeth, Hannah Arendt. Leben, Werk und Zeit. Aus dem Amerik. von Hans Günther Holl, Frankfurt a. M. 1986.

\section{Zeitzeugeninterviews}

Bondy, François (Zürich)

Jänicke, Martin (Berlin)

Lasky, Melvin J. (Berlin)

Lüthy, Herbert (Basel)

\section{Periodika}

Der Monat. Eine internationale Zeitschrift für Politik und geistiges Leben (1948-1971), zwölf Hefte in jedem Jahrgang Oktober des Jahres bis September des Folgejahres. Die Jahrgänge 1948 bis 1952, 1954 und 1959 sind online in der Central and Eastern European Online Library einsehbar: www.ceeol.com/search/journal-detail?id=391. Ost-Probleme (1949-1967); relevant sind die Ausgaben bis 1960.

Europa-Archiv 2 (1947).

\section{Fernsehsendung}

3sat-Sendung Kulturzeit vom 26. Juni 2000.

\section{Nachschlagewerke}

Biographisches Handbuch der deutschsprachigen Emigration nach 1933 (hg. vom Institut für Zeitgeschichte München und von der Research Foundation for Jewish Immigration, Inc., New York. Gesamtleitung Werner Röder und Herbert A. Strauss). Bd.I: Politik, Wirtschaft, Öffentliches Leben, München 1999. 


\section{Geschichtswissenschaft}

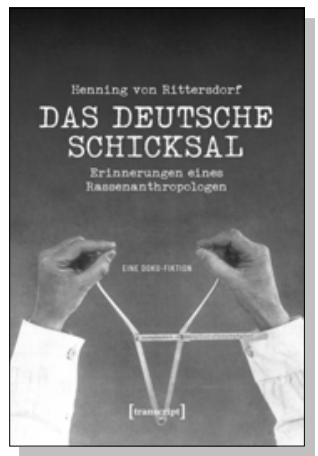

Thomas Etzemüller

Henning von Rittersdorf:

Das Deutsche Schicksal

Erinnerungen eines Rassenanthropologen.

Eine Doku-Fiktion

September 2021, 294 S., kart., Dispersionsbindung

35,00 € (DE), 978-3-8376-5936-8

E-Book:

PDF: 34,99€ (DE), ISBN 978-3-8394-5936-2

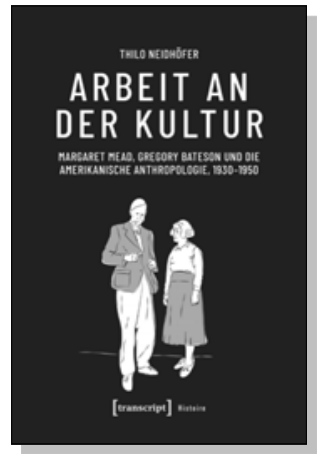

Thilo Neidhöfer

Arbeit an der Kultur

Margaret Mead, Gregory Bateson

und die amerikanische Anthropologie, 1930-1950

Juni 2021, 440 S., kart., Dispersionsbindung, 5 SW-Abbildungen 49,00€ (DE), 978-3-8376-5693-0

E-Book: kostenlos erhältlich als Open-Access-Publikation PDF: ISBN 978-3-8394-5693-4

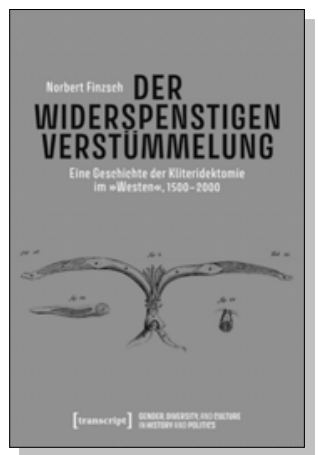

Norbert Finzsch

Der Widerspenstigen Verstümmelung

Eine Geschichte der Kliteridektomie im "Westen ", 1500-2000

Mai 2021, 528 S.,

kart., Dispersionsbindung, $30 \mathrm{SW}$-Abbildungen

49,50€ (DE), 978-3-8376-5717-3

E-Book:

PDF: 48,99€ (DE), ISBN 978-3-8394-5717-7 


\section{Geschichtswissenschaft}

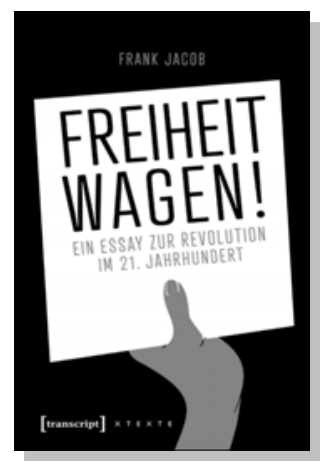

Frank Jacob

Freiheit wagen!

Ein Essay zur Revolution im 21. Jahrhundert

April 2021, 88 S., kart., Dispersionsbindung

9,90€ (DE), 978-3-8376-5761-6

E-Book: kostenlos erhältlich als Open-Access-Publikation PDF: ISBN 978-3-8394-5761-0

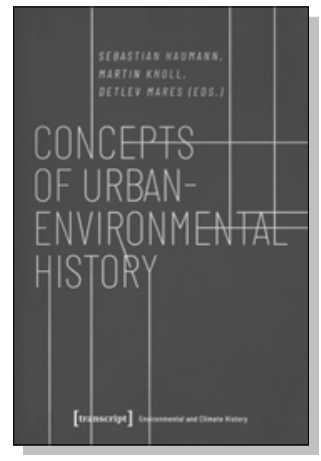

Sebastian Haumann, Martin Knoll, Detlev Mares (eds.)

Concepts of Urban-Environmental History

2020, 294 p., pb., ill.

$29,99 €(D E), 978-3-8376-4375-6$

E-Book:

PDF: $26,99 €$ (DE), ISBN 978-3-8394-4375-0

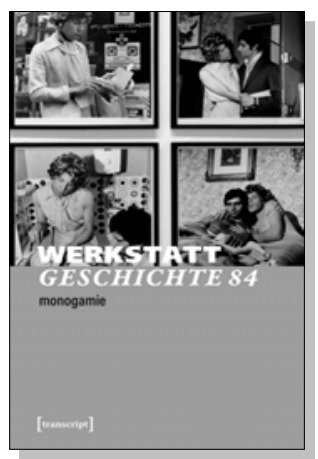

Verein für kritische Geschichtsschreibung e.V. (Hg.)

WerkstattGeschichte

2021/2, Heft 84: Monogamie

September 2021, 182 S.,

kart., Dispersionsbindung, 4 Farbabbildungen

22,00€ (DE), 978-3-8376-5344-1

E-Book:

PDF: $21,99 €$ (DE), ISBN 978-3-8394-5344-5 